\title{
REVISED SARS-CoV-2 and the role of fomite transmission: a
}

\section{systematic review [version 2; peer review: 2 approved]}

\author{
Igho J. Onakpoya (D1) Carl J. Heneghan (D1), Elizabeth A. Spencer (D1, \\ Jon Brassey (iD2, Annette Plüddemann1, David H. Evans (i)3, John M. Conly4, \\ Tom Jefferson ${ }^{1}$
}

${ }^{1}$ Nuffield Department of Primary Care Health Sciences, University of Oxford, Oxford, OX2 6GG, UK

${ }^{2}$ Trip Database Ltd, Newport, NP20 3PS, UK

${ }^{3}$ Department of Medical Microbiology \& Immunology, Li Ka Shing Institute of Virology, Alberta, Canada

${ }^{4}$ University of Calgary and Alberta Health Services, Calgary, AB T2N 4Z6, Canada

V2 First published: 24 Mar 2021, 10:233

https://doi.org/10.12688/f1000research.51590.1

Second version: 26 May 2021, 10:233

https://doi.org/10.12688/f1000research.51590.2

Latest published: 14 Jun 2021, 10:233

https://doi.org/10.12688/f1000research.51590.3

\section{Abstract}

Background: SARS-CoV-2 RNA has been detected in fomites which suggests the virus could be transmitted via inanimate objects. However, there is uncertainty about the mechanistic pathway for such transmissions. Our objective was to identify, appraise and summarise the evidence from primary studies and systematic reviews assessing the role of fomites in transmission.

Methods: This review is part of an Open Evidence Review on Transmission Dynamics of SARS-CoV-2. We conduct ongoing searches using WHO Covid-19 Database, LitCovid, medRxiv, and Google Scholar; assess study quality based on five criteria and report important findings on an ongoing basis.

Results: We found 64 studies: 63 primary studies and one systematic review $(n=35)$. The settings for primary studies were predominantly in hospitals (69.8\%) including general wards, ICU and SARS-CoV-2 isolation wards. There were variations in the study designs including timing of sample collection, hygiene procedures, ventilation settings and cycle threshold. The overall quality of reporting was low to moderate. The frequency of positive SARS-CoV-2 tests across 51 studies (using RT-PCR) ranged from $0.5 \%$ to $75 \%$. Cycle threshold values ranged from 20.8 to 44.1. Viral concentrations were reported in 17 studies; however, discrepancies in the methods for estimation prevented comparison. Eleven studies (17.5\%) attempted viral culture, but none found a cytopathic effect. Results of the systematic review showed that healthcare settings were most frequently tested (25/35, $71.4 \%)$, but laboratories reported the highest frequency of contaminated surfaces $(20.5 \%, 17 / 83)$.

Conclusions: The majority of studies report identification of SARS-
Open Peer Review

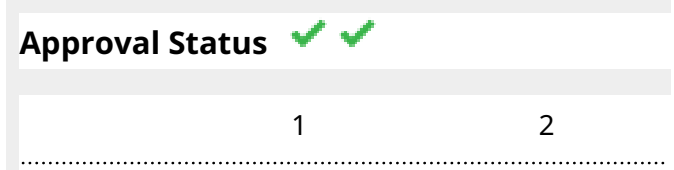

version 3

(revision)

14 Jun 2021

version 2

(revision)

26 May 2021

version 1

24 Mar 2021

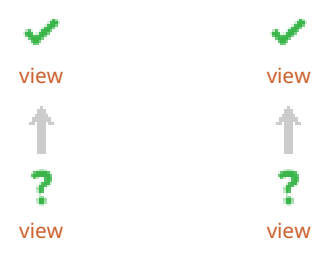

1. Emanuel Goldman (DD, New Jersey Medical

School, Newark, USA

2. Ana Karina Pitol Garcia (iD), Imperial College London, London, UK

Any reports and responses or comments on the article can be found at the end of the article. 
CoV-2 RNA on inanimate surfaces; however, there is a lack of evidence demonstrating the recovery of viable virus. Lack of positive viral cultures suggests that the risk of transmission of SARS-CoV-2 through fomites is low. Heterogeneity in study designs and methodology prevents comparisons of findings across studies. Standardized guidelines for conducting and reporting research on fomite transmission is warranted.

Keywords

Fomites, transmission, COVID-19, systematic review

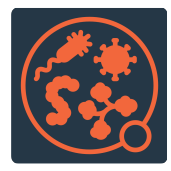

This article is included in the Pathogens

gateway.

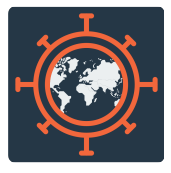

This article is included in the Emerging Diseases

and Outbreaks gateway.

This article is included in the Coronavirus

collection. 
Corresponding author: Igho J. Onakpoya (igho.onakpoya@conted.ox.ac.uk)

Author roles: Onakpoya IJ: Data Curation, Formal Analysis, Writing - Original Draft Preparation, Writing - Review \& Editing; Heneghan CJ: Conceptualization, Data Curation, Formal Analysis, Funding Acquisition, Methodology, Project Administration, Writing - Original Draft Preparation, Writing - Review \& Editing; Spencer EA: Data Curation, Formal Analysis, Writing - Original Draft Preparation, Writing Review \& Editing; Brassey J: Data Curation, Formal Analysis, Resources, Writing - Original Draft Preparation, Writing - Review \& Editing; Plüddemann A: Writing - Original Draft Preparation, Writing - Review \& Editing; Evans DH: Methodology, Writing - Review \& Editing; Conly JM: Methodology, Writing - Original Draft Preparation, Writing - Review \& Editing; Jefferson T: Conceptualization, Data Curation, Formal Analysis, Funding Acquisition, Methodology, Writing - Original Draft Preparation, Writing - Review \& Editing

Competing interests: $\mathrm{CJH}$ holds grant funding from the NIHR, the NIHR School of Primary Care Research, the NIHR BRC Oxford and the World Health Organization for a series of Living rapid review on the modes of transmission of SARs-CoV-2 reference WHO registration No2020/1077093. He has received financial remuneration from an asbestos case and given legal advice on mesh and hormone pregnancy tests cases. He has received expenses and fees for his media work including occasional payments from BBC Radio 4 Inside Health and The Spectator. He receives expenses for teaching EBM and is also paid for his GP work in NHS out of hours (contract Oxford Health NHS Foundation Trust). He has also received income from the publication of a series of toolkit books and for appraising treatment recommendations in non-NHS settings. He is Director of CEBM and is an NIHR Senior Investigator. TJ was in receipt of a Cochrane Methods Innovations Fund grant to develop guidance on the use of regulatory data in Cochrane reviews (2015-018). In 2014-2016, he was a member of three advisory boards for Boehringer Ingelheim. TJ was a member of an independent data monitoring committee for a Sanofi Pasteur clinical trial on an influenza vaccine. TJ is occasionally interviewed by market research companies about phase I or II pharmaceutical products for which he receives fees (current). TJ was a member of three advisory boards for Boehringer Ingelheim (2014-16). TJ was a member of an independent data monitoring committee for a Sanofi Pasteur clinical trial on an influenza vaccine (2015-2017). TJ is a relator in a False Claims Act lawsuit on behalf of the United States that involves sales of Tamiflu for pandemic stockpiling. If resolved in the United States' favor, he would be entitled to a percentage of the recovery. TJ is co-holder of a Laura and John Arnold Foundation grant for development of a RIAT support centre (2017-2020) and Jean Monnet Network Grant, 2017-2020 for The Jean Monnet Health Law and Policy Network. TJ is an unpaid collaborator to the project Beyond Transparency in Pharmaceutical Research and Regulation led by Dalhousie University and funded by the Canadian Institutes of Health Research (2018-2022). TJ consulted for Illumina LLC on next generation gene sequencing (2019-2020). TJ was the consultant scientific coordinator for the HTA Medical Technology programme of the Agenzia per i Serivizi Sanitari Nazionali (AGENAS) of the Italian MoH (2007-2019). TJ is Director Medical Affairs for BC Solutions, a market access company for medical devices in Europe. TJ is funded by NIHR UK and the World Health Organization (WHO) to update Cochrane review A122, "Physical Interventions to interrupt the spread of respiratory viruses". TJ is funded by Oxford University to carry out a living review on the transmission epidemiology of COVID-19. Since 2020, TJ receives fees for articles published by The Spectator and other media outlets. TJ is part of a review group carrying out "Living rapid literature review on the modes of transmission of SARS-CoV-2 (WHO Registration 2020/1077093-0)". He is a member of the WHO COVID-19 Infection Prevention and Control Research Working Group. DHE has been awarded U.S. patents as a co-inventor of related oncolytic virus technologies and is a co-owner of Prophysis Inc., which retains a partial interest in the licensing rights for these technologies. JMC holds grants from the Canadian Institutes for Health Research on acute and primary care preparedness for COVID-19 in Alberta, Canada and was the primary local Investigator for a Staphylococcus aureus vaccine study funded by Pfizer for which all funding was provided only to the University of Calgary. He also received support from the Centers for Disease Control and Prevention (CDC) to attend an Infection Control Think Tank Meeting. IJO, EAS, JB and AP have no interests to disclose.

Grant information: The review was funded by the World Health Organization: Living rapid review on the modes of transmission of SARs-CoV-2 reference WHO registration No2020/1077093. CH and ES also receive funding support from the NIHR SPCR Evidence Synthesis Working Group project 390.

The funders had no role in study design, data collection and analysis, decision to publish, or preparation of the manuscript.

Copyright: ( 2021 Onakpoya IJ et al. This is an open access article distributed under the terms of the Creative Commons Attribution License, which permits unrestricted use, distribution, and reproduction in any medium, provided the original work is properly cited.

How to cite this article: Onakpoya IJ, Heneghan CJ, Spencer EA et al. SARS-CoV-2 and the role of fomite transmission: a systematic review [version 2; peer review: 2 approved] F1000Research 2021, 10:233 https://doi.org/10.12688/f1000research.51590.2

First published: 24 Mar 2021, 10:233 https://doi.org/10.12688/f1000research.51590.1 


\section{REVISED Amendments from Version 1}

We have revised the conclusions of the abstract, expanded the reporting of the methods for risk of bias assessment and revised the discussion to clarify the disconnect between detection of SARS-COV-RNA versus infectious SARS-CoV-2.

Any further responses from the reviewers can be found at the end of the article

\section{Introduction}

The SARS-CoV-2 (COVID-19) pandemic is a major public health concern. According to WHO statistics, there have been over 90 million confirmed cases and over two million deaths globally as of 18th January 2021 ${ }^{1}$. Although many national governments have implemented control measures and vaccines are now being approved and administered, the rate of infection has not subsided as anticipated. Understanding the modes of transmission of SARS-CoV-2 is critical to developing effective public health and infection prevention measures to interrupt the chains of transmission ${ }^{2}$. Current evidence suggests SARS-CoV-2 is primarily transmitted via respiratory droplets and direct contact $^{3}$, but other transmission routes have been suggested aerosol and fomites.

While the respiratory, airborne, and direct contact modes of transmission have been investigated in detail, the role of fomites in the transmission of SARS-CoV-2 is less clear. Findings from previous systematic reviews have shown that viruses from the respiratory tract, such as coronaviridae, can persist on inanimate surfaces for some days ${ }^{4}$, and it has been suggested that SARS-CoV-2 can be transmitted indirectly through fomites or surfaces ${ }^{5}$. However, some authors have reported that there is a low risk of transmission of SARS-CoV-2 through fomites ${ }^{6,7}$ and others have reported that the risk of such transmission is exaggerated ${ }^{8}$.

Several studies investigating the role of fomites in SARS-CoV-2 are now being published but the evidence from such studies has not been systematically evaluated. The objective of this review was to identify, appraise and summarize the evidence from primary studies and systematic reviews investigating the role of fomites in the transmission of SARS-CoV-2. Terminology for this article can be found in Box 1.

Box 1. Terminology

Fomite: Object or surface contaminated by infected droplets. The contamination can occur through sneezing, coughing on, or touching surfaces

Viral load: A measure of the number of viral particles present in an individual

Cycle threshold: The number of cycles required for the fluorescent signal to cross the threshold. Ct levels are inversely proportional to the amount of target nucleic acid in the sample

'World Health Organization. Q\&A: How is COVID-19

transmitted? https://www.who.int/vietnam/news/detail/14-07-

2020-q-a-how-is-covid-19-transmitted

${ }^{2}$ https://www.cebm.net/covid-19/sars-cov-2-viral-load-and-theseverity-of-covid-19/

${ }^{3}$ https://www.ncbi.nlm.nih.gov/pmc/articles/PMC7521909/

\section{Methods}

We are undertaking an open evidence review investigating factors and circumstances that impact on the transmission of SARS-CoV-2, based on our published protocol last updated on the 1 December 2020 (archived protocol: Extended data: Appendix 19 ; original protocol: https://www.cebm.net/evidencesynthesis/transmission-dynamics-of-covid-19/). Briefly, this review aims to identify, appraise, and summarize the evidence (from studies peer-reviewed or awaiting peer review) relating to the role of fomites in the transmission of SARS-CoV-2 and the factors influencing transmissibility. We conducted an ongoing search in WHO Covid-19 Database, LitCovid, medRxiv, and Google Scholar for SARS-CoV-2 for keywords and associated synonyms. The searches for this update were conducted up to 20th December 2020. No language restrictions were imposed (see Extended data: Appendix 2 for the search strategies ${ }^{9}$.

We included studies of any design that investigated fomite transmission. Predictive or modelling studies were excluded. Results were reviewed for relevance and for articles that looked particularly relevant, forward citation matching was undertaken and relevant results were identified. We assessed the risk of bias using five domains from the QUADAS-2 criteria $^{10}$; we adapted this tool because the included studies were not designed as diagnostic accuracy studies. The domains assessed were: (i) study description - was there sufficient description of methods to enable replication of the study? (ii) sample sources - was there a clear description of sample sources? (iii) description of results - was the reporting of study results and analysis appropriate? (iv) risk of bias - did the authors acknowledge any potential biases, if yes were any attempts made to address these biases? (v) applicability - is there any concern that the interpretation of test results differs from the study question? For each bias domain, the risk was judged as "low", "unclear" or "high". We extracted the following information from included studies: study characteristics, population, main methods, and associated outcomes including the number of swab samples taken with frequency and timing of samples, and cycle thresholds and samples concentrations where reported. We also extracted information on viral cultures including the methods. One reviewer (IJO) assessed the risk of bias and extracted data from the included studies, and these were independently checked by a second reviewer (EAS). We presented the results in tabular format, and bar charts used to present the frequency of positive tests. Because of substantial heterogeneity across the included studies, we did not perform a meta-analysis.

\section{Results}

We identified 709 non-duplicate citations of which 91 were considered eligible (Figure 1). We excluded 27 full-text studies because they did not meet our inclusion criteria (see Extended data: Appendix $3^{9}$ for the list of excluded studies and reasons for exclusion). Finally, we included 64 studies: 63 primary studies and one systematic review (see Extended data: Appendix 4; characteristics of studies in Table 1 and Table $2^{9}$ ).

\section{Quality of included studies}

None of the included studies were linked to or mentioned a published protocol. The risk of bias of the included studies is 


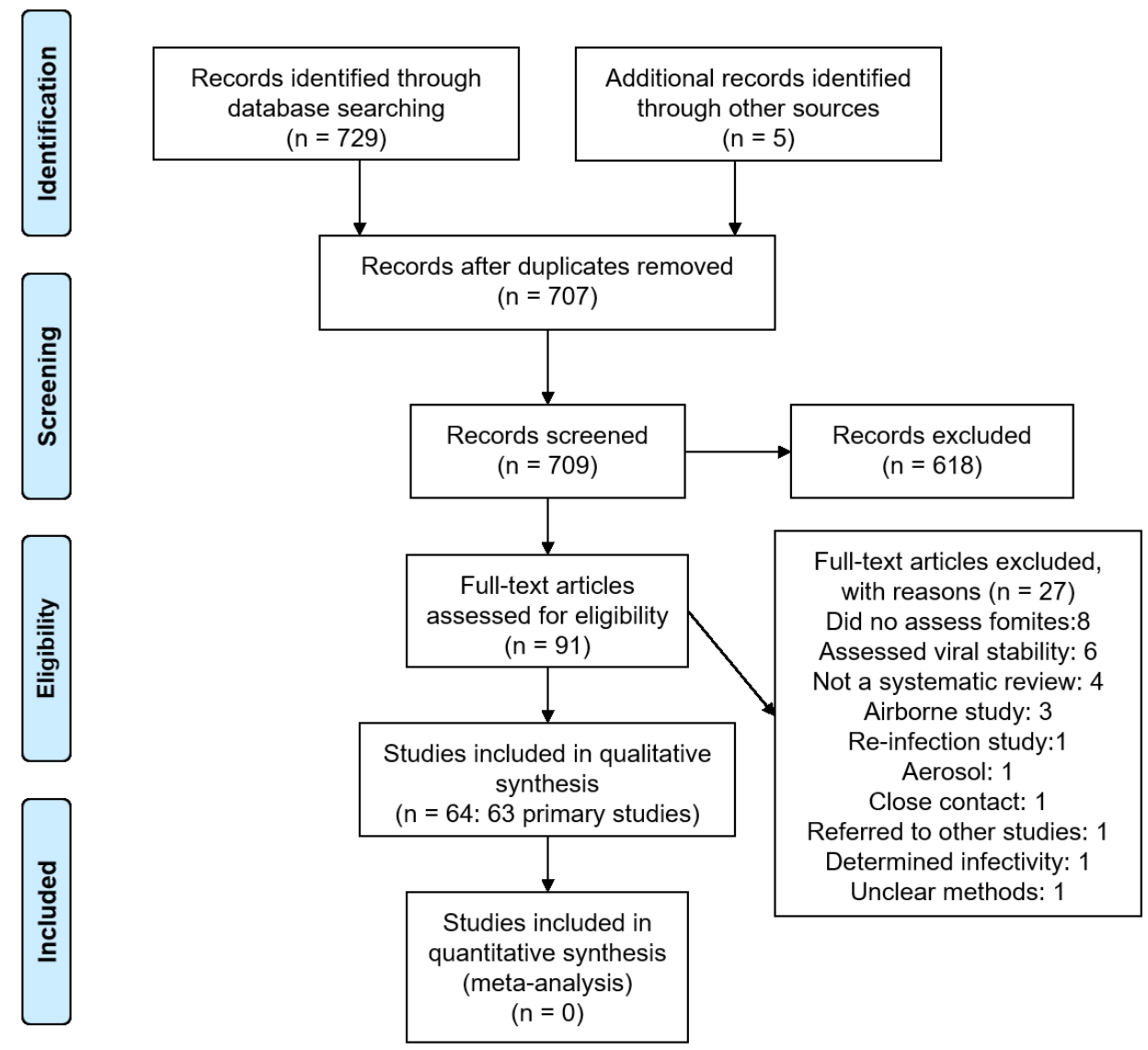

Figure 1. Flow diagram showing the process for inclusion of studies assessing fomites transmission in SARS-CoV-2.

shown in Table 4. Less than half of the studies (47.6\%) adequately reported the methods used, and none used methods to minimise bias. The overall quality of the studies was rated low to moderate (see Figure 2).

\section{Reviews}

We found one "systematic review" investigating the role of fomites [Bedrosian 2020] (Table 2). The authors searched two electronic sources - articles were last downloaded on July 10, 2020. There was no published protocol, and the authors did not assess the quality of included studies. A total of 35 relevant studies were included. Over half of the studies $(25 / 35,75 \%)$ were conducted in healthcare settings, and four compared environmental contamination before and after standard disinfection procedures. No study assessed viral infectivity or viability, but all tested the presence or absence of SARS-CoV-2 RNA.

\section{Primary studies}

We found 63 primary studies (Table 1). In general, the studies did not report any hypothesis but investigated epidemiological or mechanistic evidence for fomite transmission. Forty-one studies $(65.1 \%)$ were conducted in Asia, 15 (23.8\%) in Europe, five (7.9\%) in North America, and one each in Africa and South America (1.6\% each). A total of 44 studies were conducted exclusively in hospital settings, two in hospital and quarantine facilities, three in the laboratory, and the remaining in other non-healthcare settings (public places, community, banknotes, workplace, cruise ship, quarantine rooms and hospital outdoors). Four studies were conducted exclusively in ICU and another three in ICU plus hospital wards. Five studies used before and after study design.

In 59 studies (96.7\%), fomite transmission was examined in high-frequency touch surfaces (Table 1); the remaining four studies examined circulating banknotes (1), disposable chopsticks (1) hospital staff PPE (1), and unspecified (1). The timing and frequency of sample collection and disinfection procedures were heterogeneous across studies (see Table 3). Fourteen studies (23\%) performed sample collection before disinfection procedures, five studies collected samples before and after disinfection procedures, while 11 studies collected samples after disinfection. In 33 studies, the timing of sampling in relation to disinfection was not specified. In one study [Ryu 2020], disinfection procedures were not performed as required because of a lack of PPE and staff being afraid of contracting SARS-CoV-2. The number of samples per study ranged from five [Jin 2020] to 5400 [Marshall 2020].

Eleven studies (17.5\%) set out to perform viral cultures; nine of these utilised the Vero E6 cell lines method while two did not specify the method used (see Table 1). Thirteen studies 


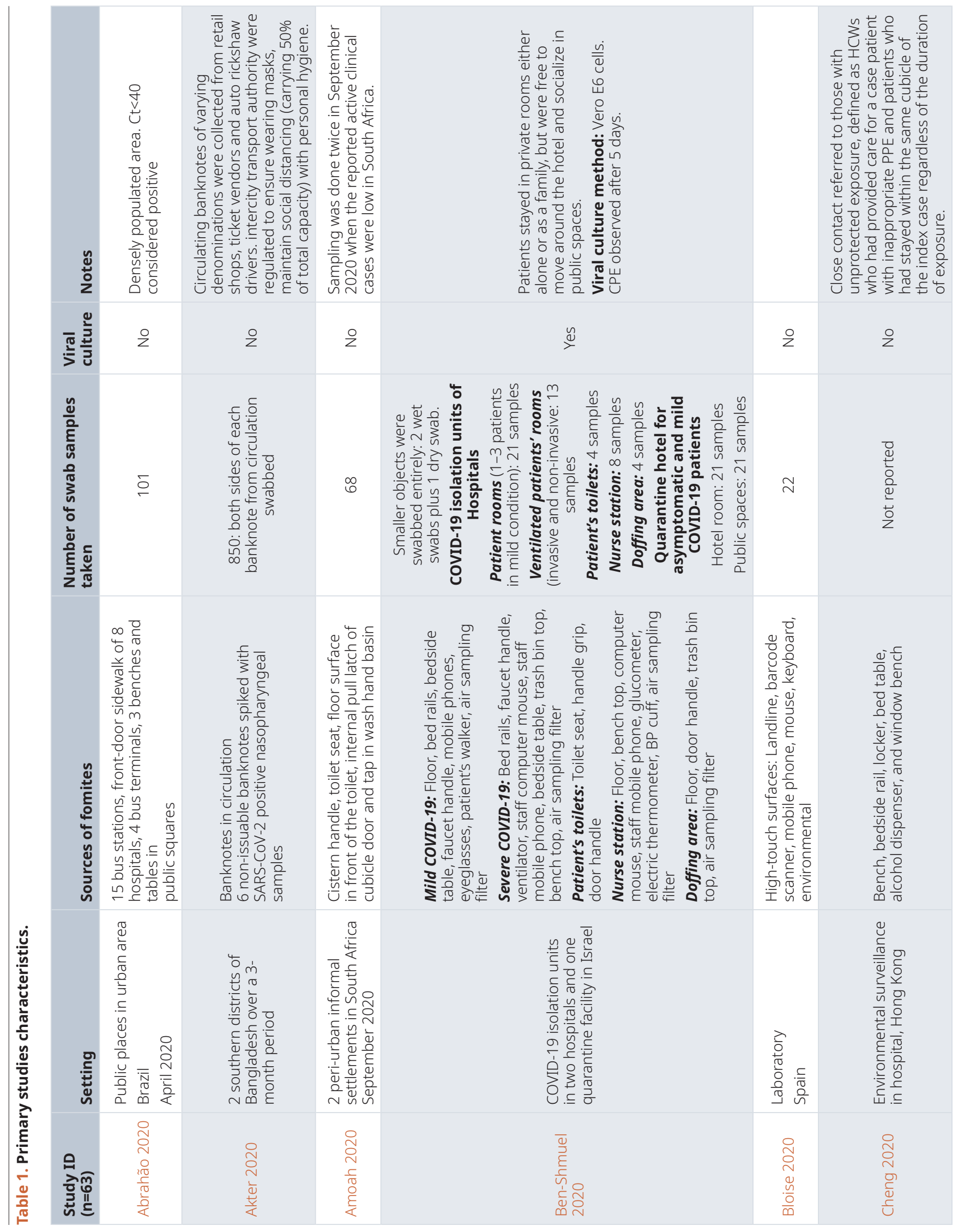




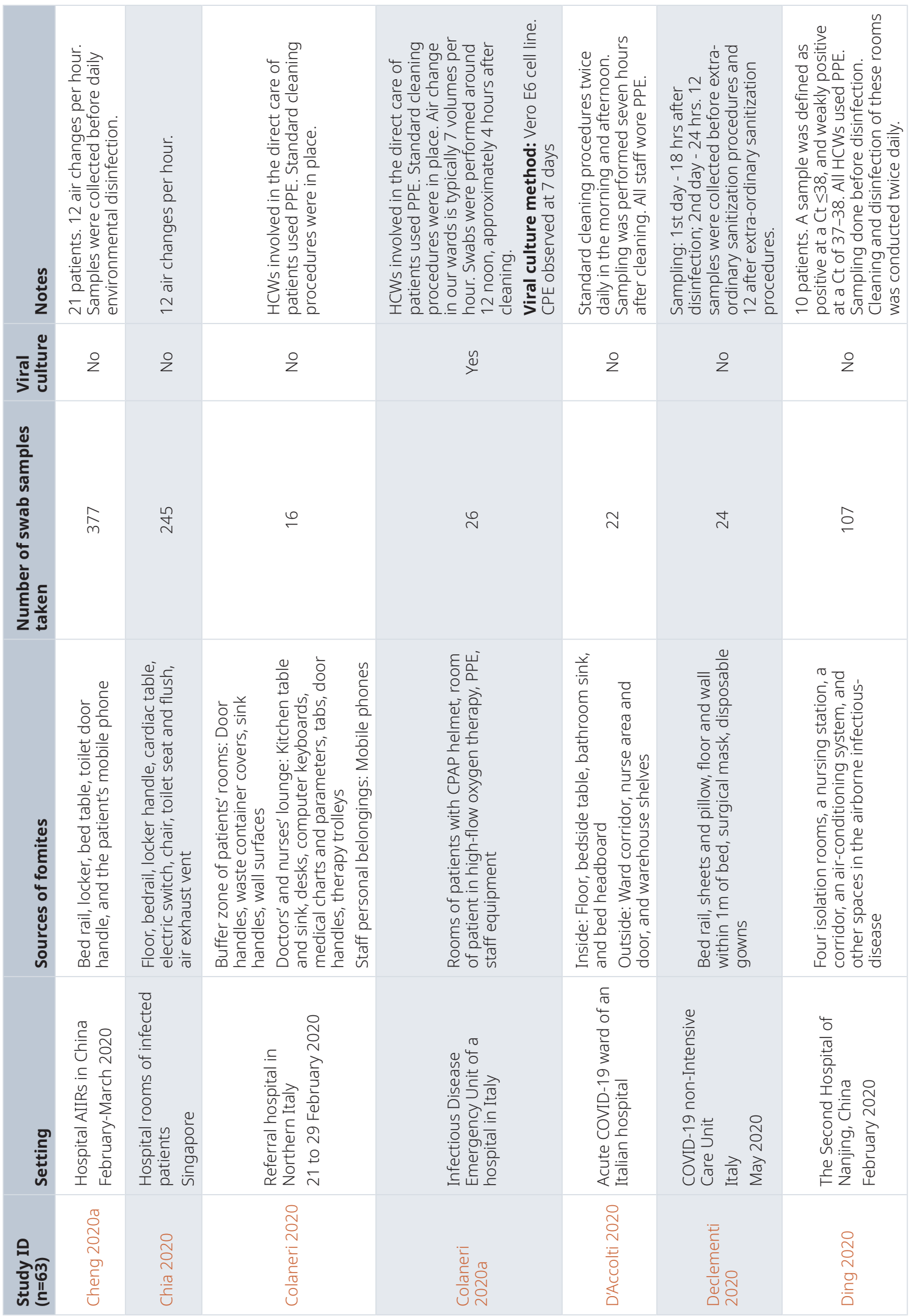




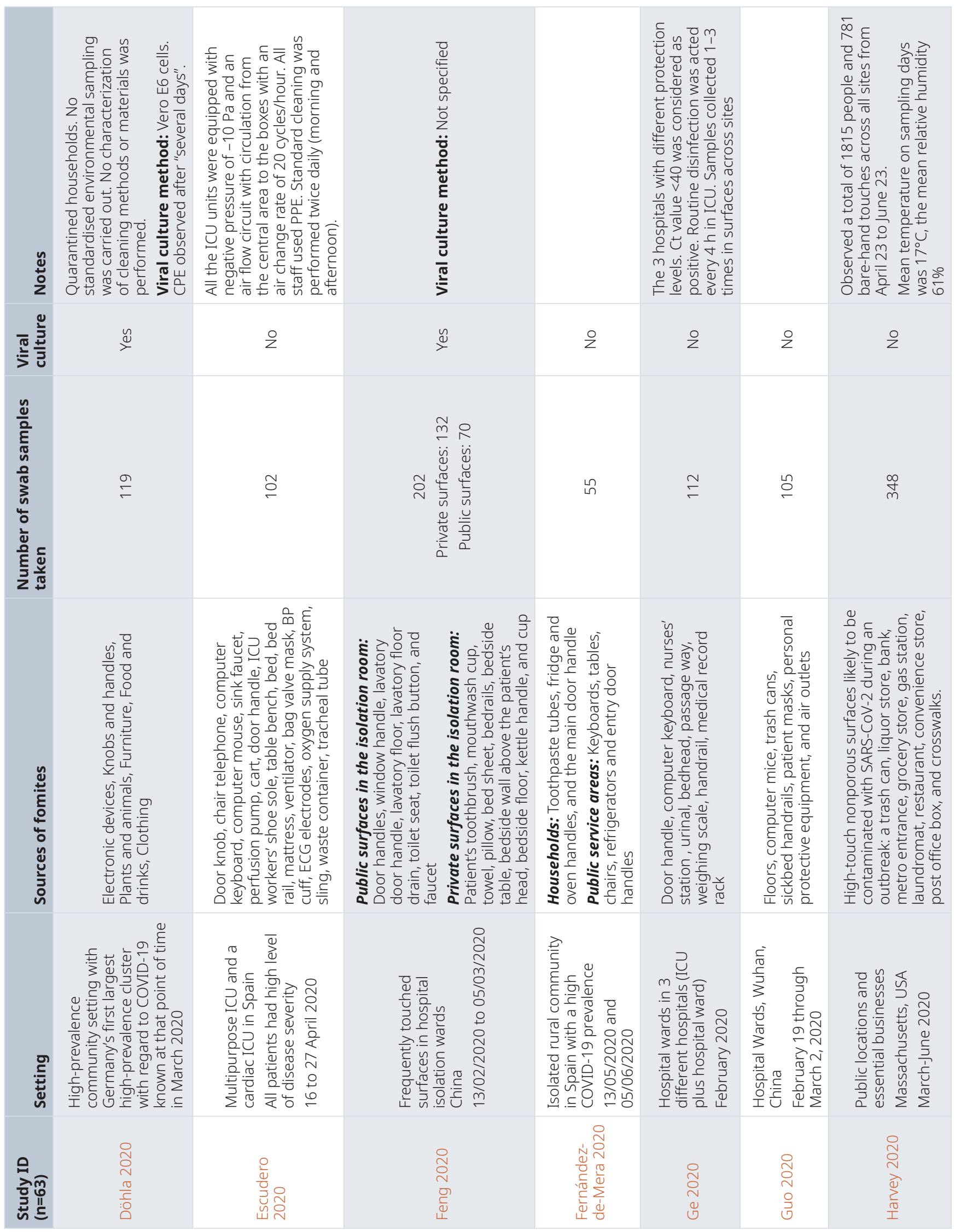




\begin{tabular}{|c|c|c|c|c|c|c|c|c|}
\hline $\begin{array}{l}\text { पै } \\
\text { ثै }\end{array}$ & & 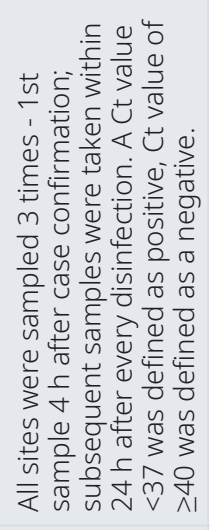 & 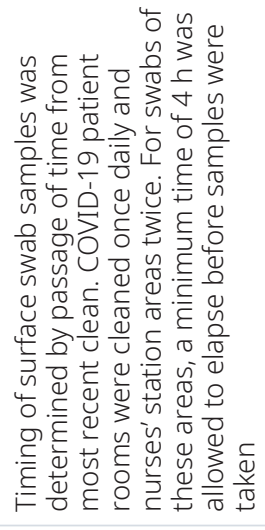 & 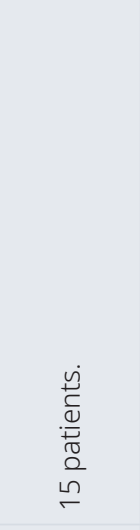 & 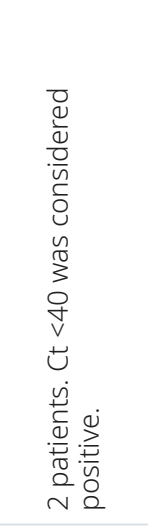 & 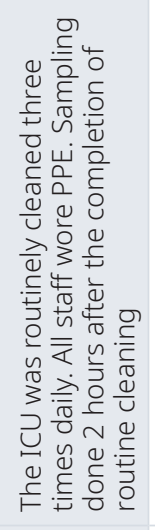 & 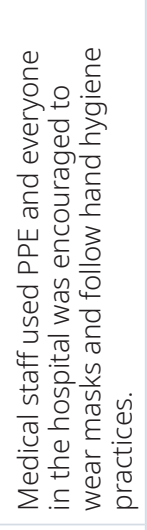 & 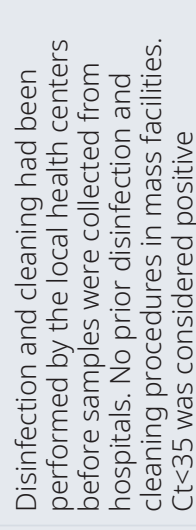 \\
\hline 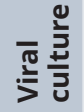 & z & zo & ㅇ & z & z & z & z & zo \\
\hline 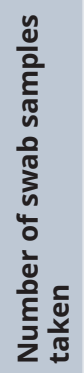 & $\stackrel{\nabla}{\sim}$ & $\mathscr{q}$ & $\bar{\infty}$ & $\stackrel{m}{\sim}$ & $\approx$ & 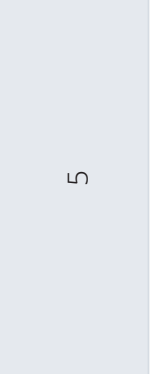 & 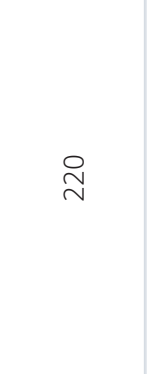 & $\infty$ \\
\hline 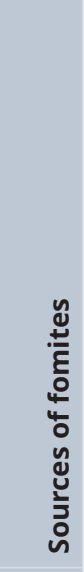 & 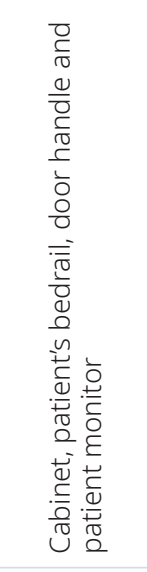 & 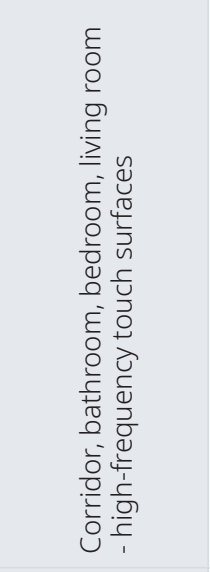 & 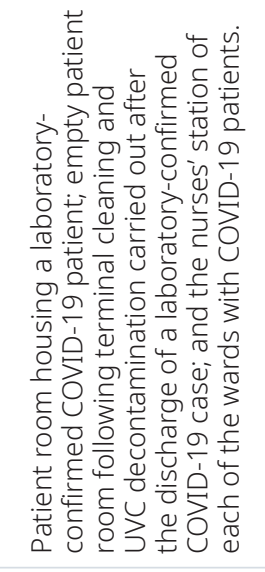 & 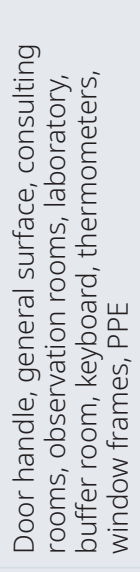 & 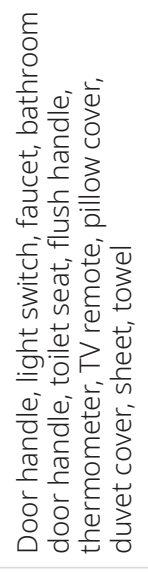 & 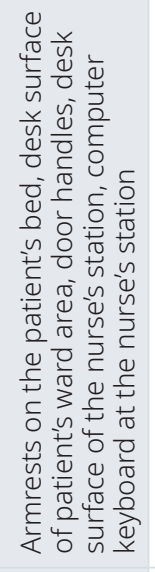 & 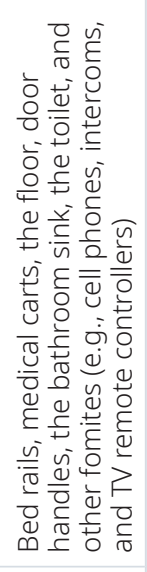 & 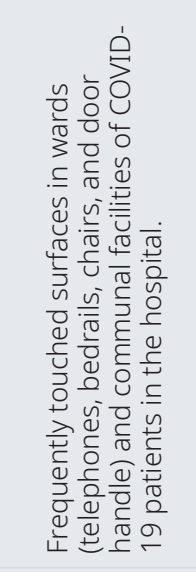 \\
\hline & 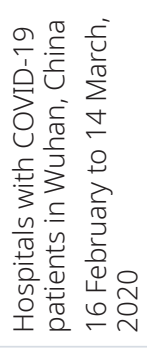 & 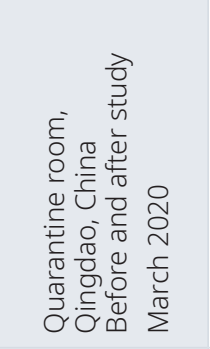 & 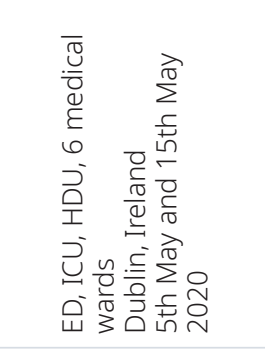 & 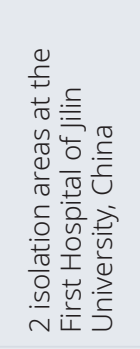 & 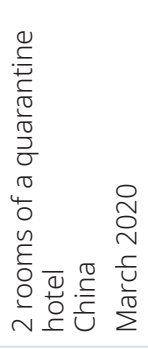 & 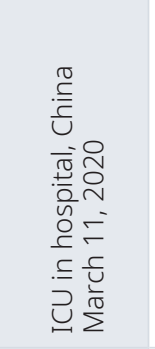 & 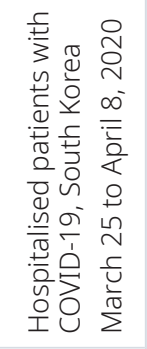 & 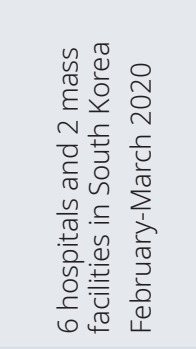 \\
\hline 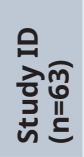 & $\begin{array}{l}\text { ָे } \\
\text { ㄱ. } \\
\text { 고 }\end{array}$ & $\begin{array}{l}\text { D̃ } \\
\text { Dे } \\
\text { İ } \\
\text { בิ }\end{array}$ & 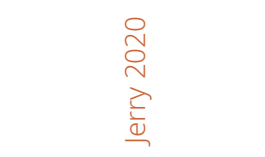 & $\begin{array}{l}\text { ్. } \\
\text { ్. } \\
\text { On } \\
\stackrel{\underline{0}}{=}\end{array}$ & 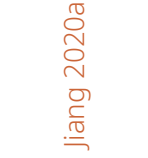 & 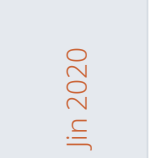 & 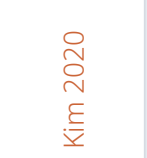 & 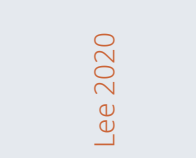 \\
\hline
\end{tabular}




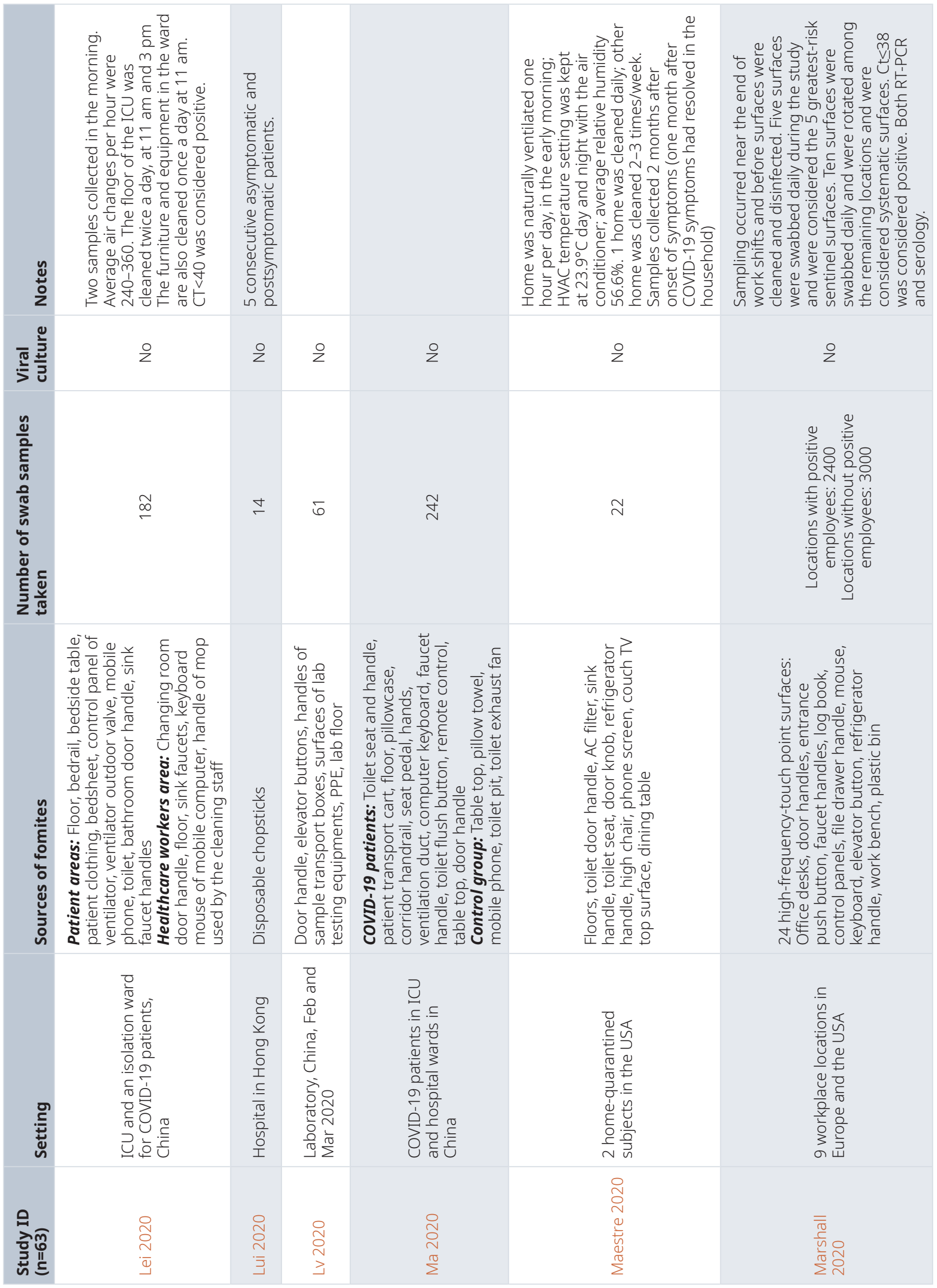




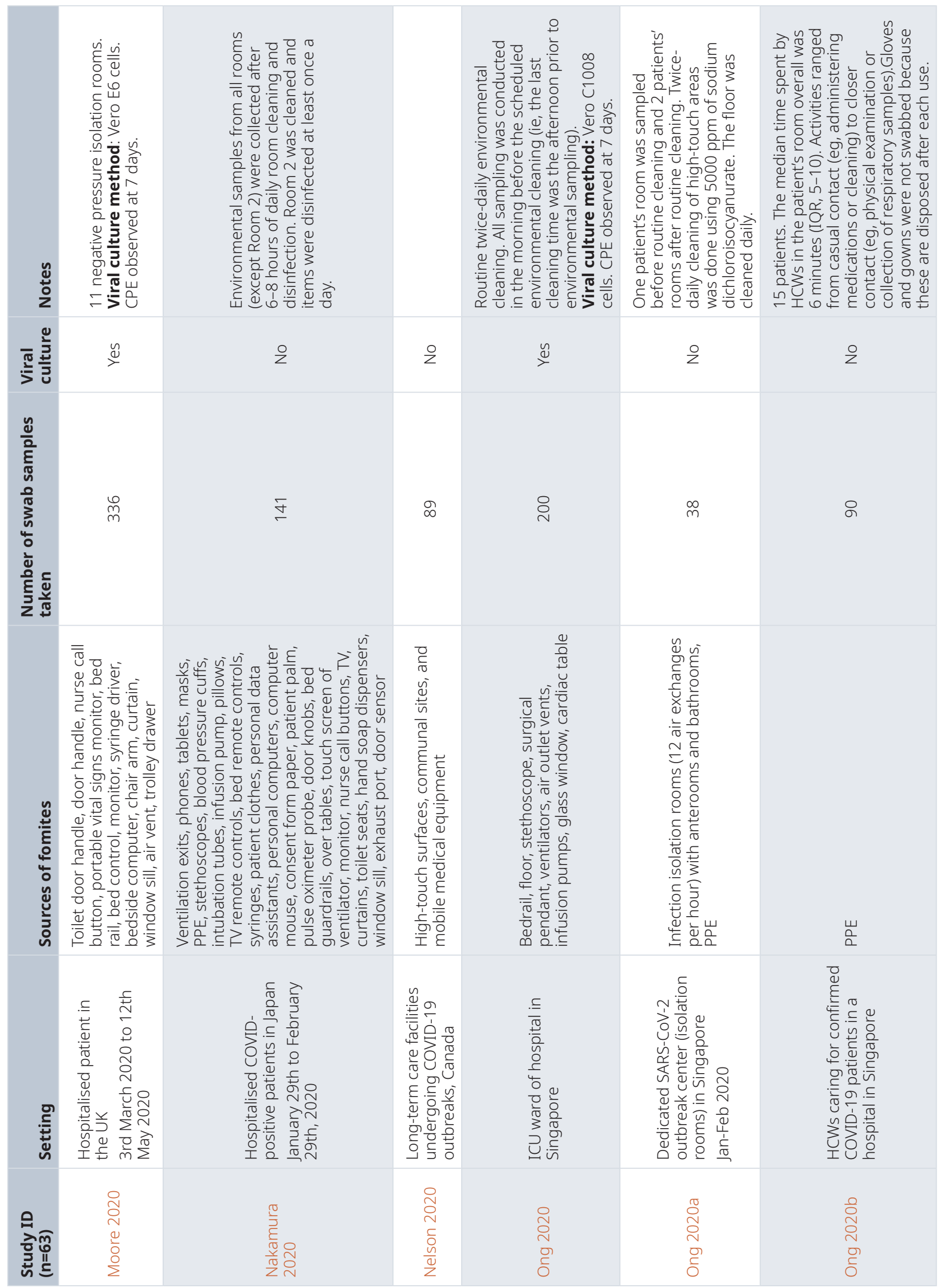




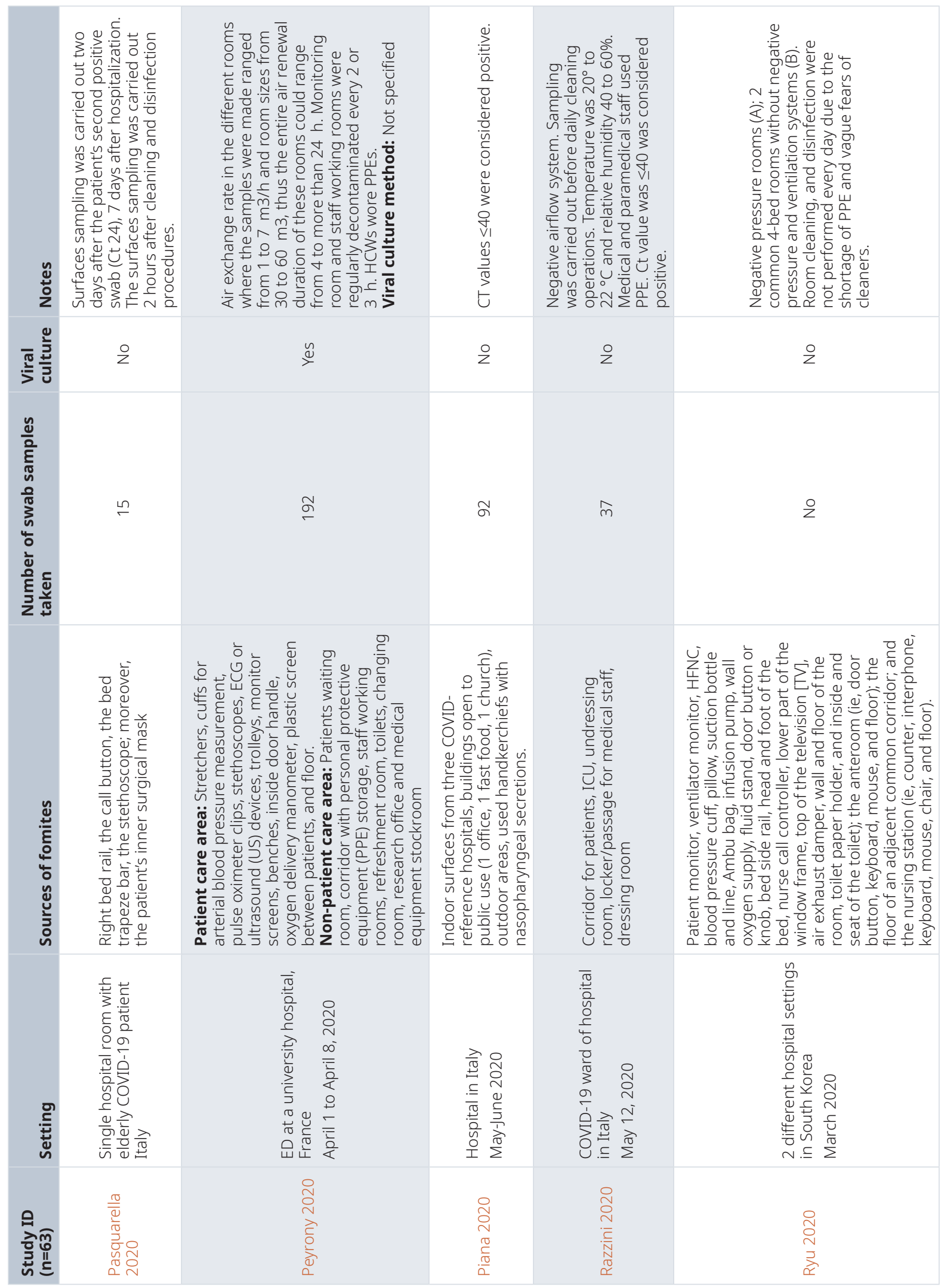




\begin{tabular}{|c|c|c|c|c|c|c|}
\hline $\begin{array}{l}y \\
\stackrel{y}{0} \\
\text { z }\end{array}$ & 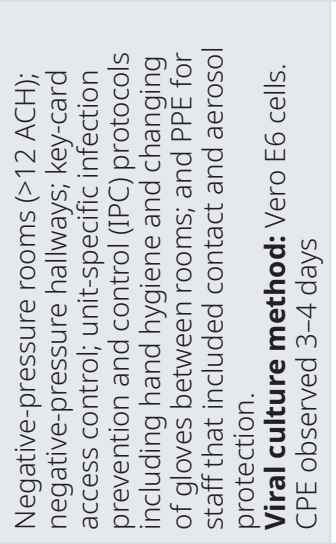 & 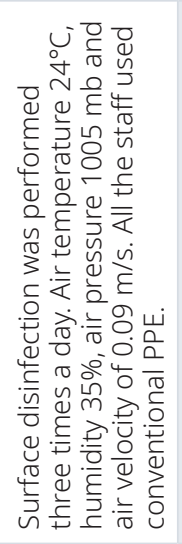 & 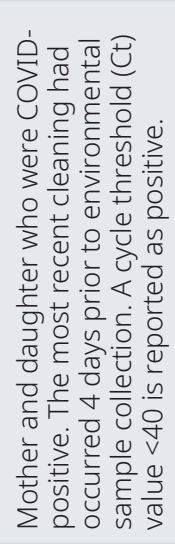 & 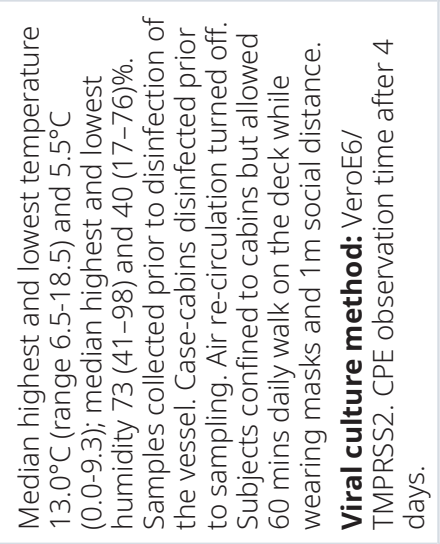 & 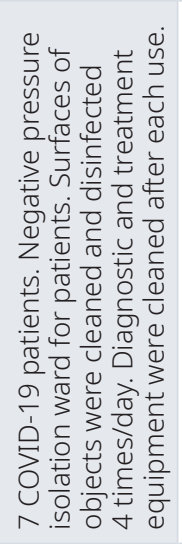 & 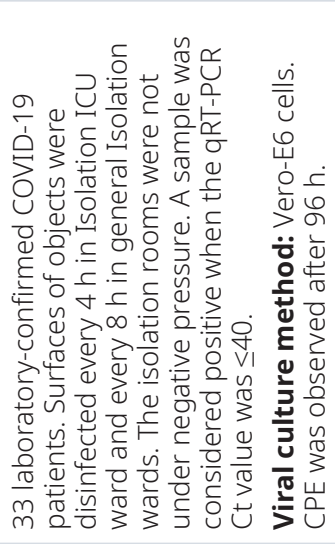 \\
\hline$\stackrel{\frac{0}{5}}{\frac{0}{5}}$ & $\stackrel{\breve{\nu}}{\supset}$ & z & z & 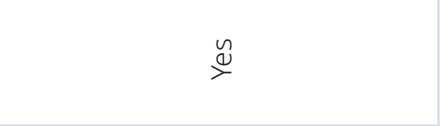 & z & 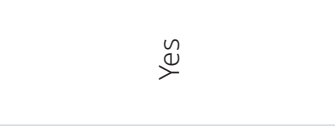 \\
\hline 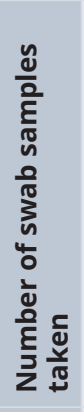 & 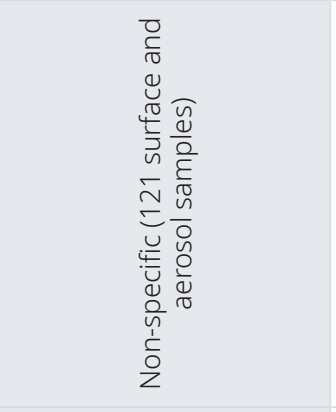 & $\stackrel{\circ}{\circ}$ & $\stackrel{\simeq}{\simeq}$ & $\overline{8}$ & $\widetilde{\sigma}$ & $\stackrel{\text { If }}{+}$ \\
\hline 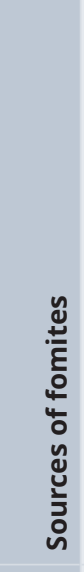 & 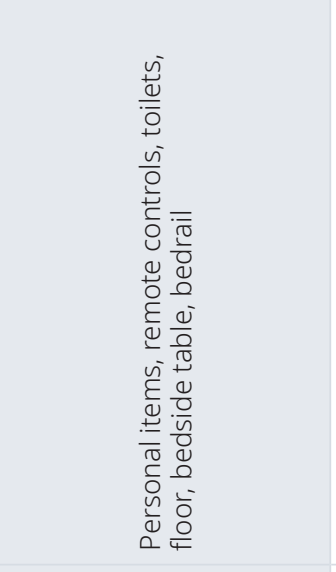 & 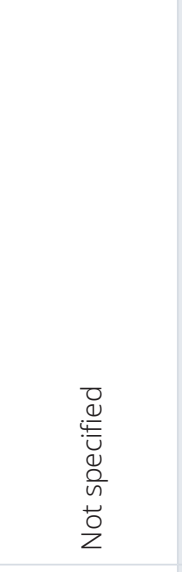 & 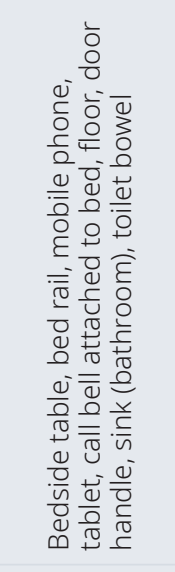 & 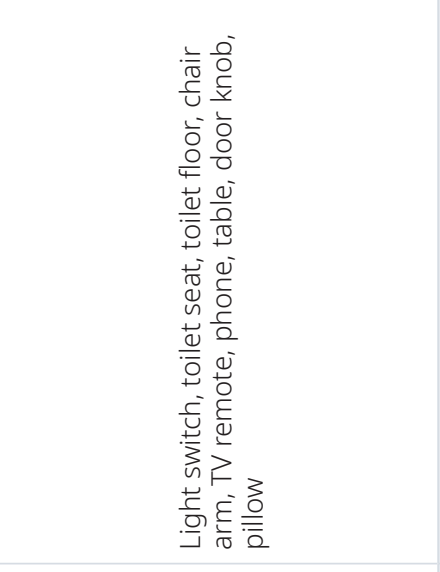 & 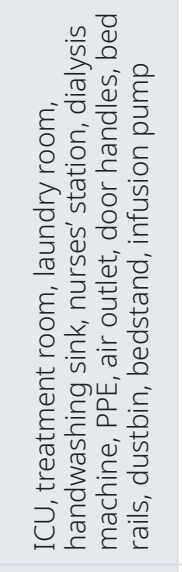 & 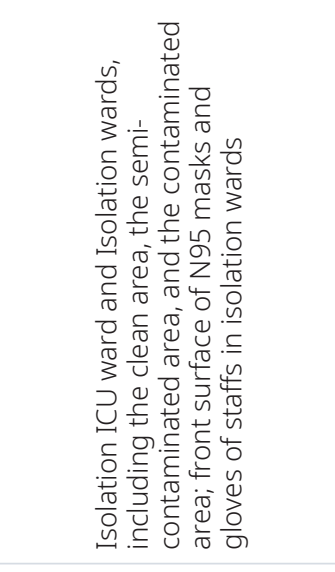 \\
\hline & 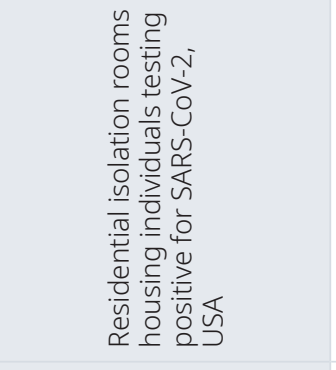 & 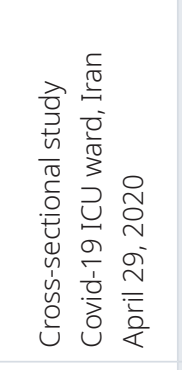 & 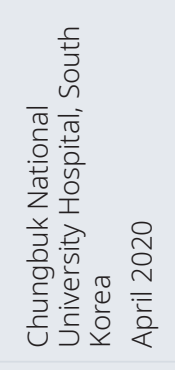 & 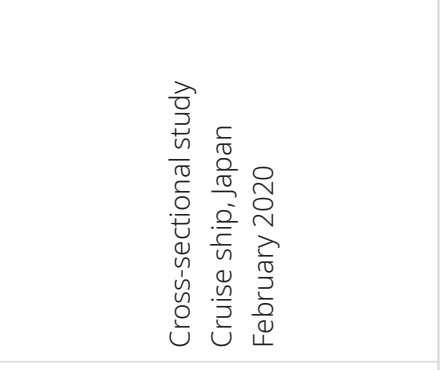 & 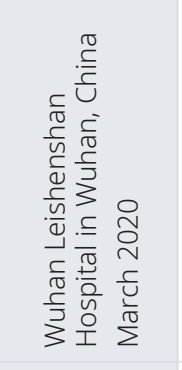 & 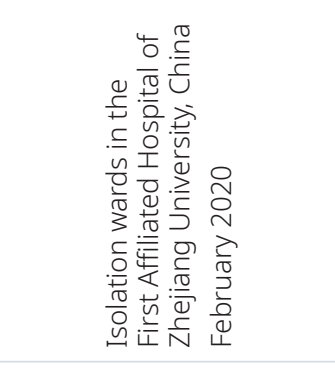 \\
\hline 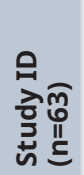 & 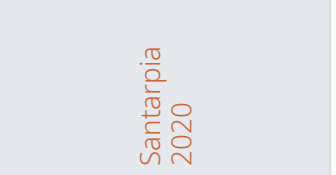 & 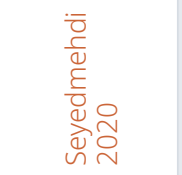 & 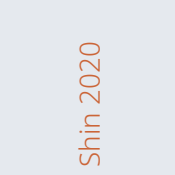 & 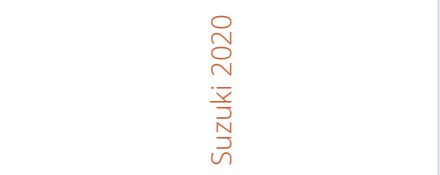 & $\begin{array}{l}\text { ㄱ. } \\
\text { D } \\
\text { N } \\
\text { On } \\
\frac{1}{\pi} \\
3\end{array}$ & 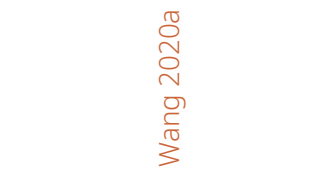 \\
\hline
\end{tabular}




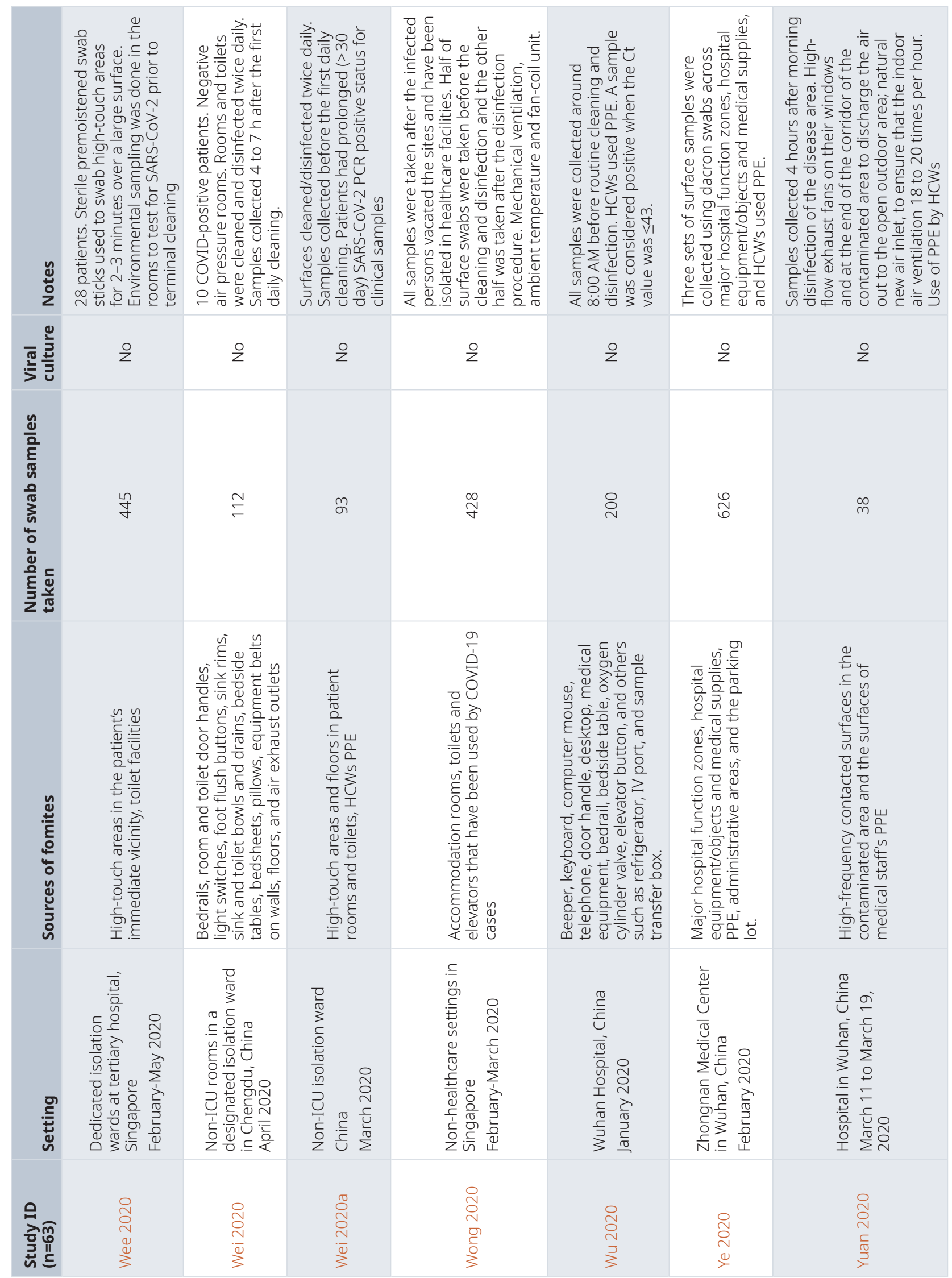




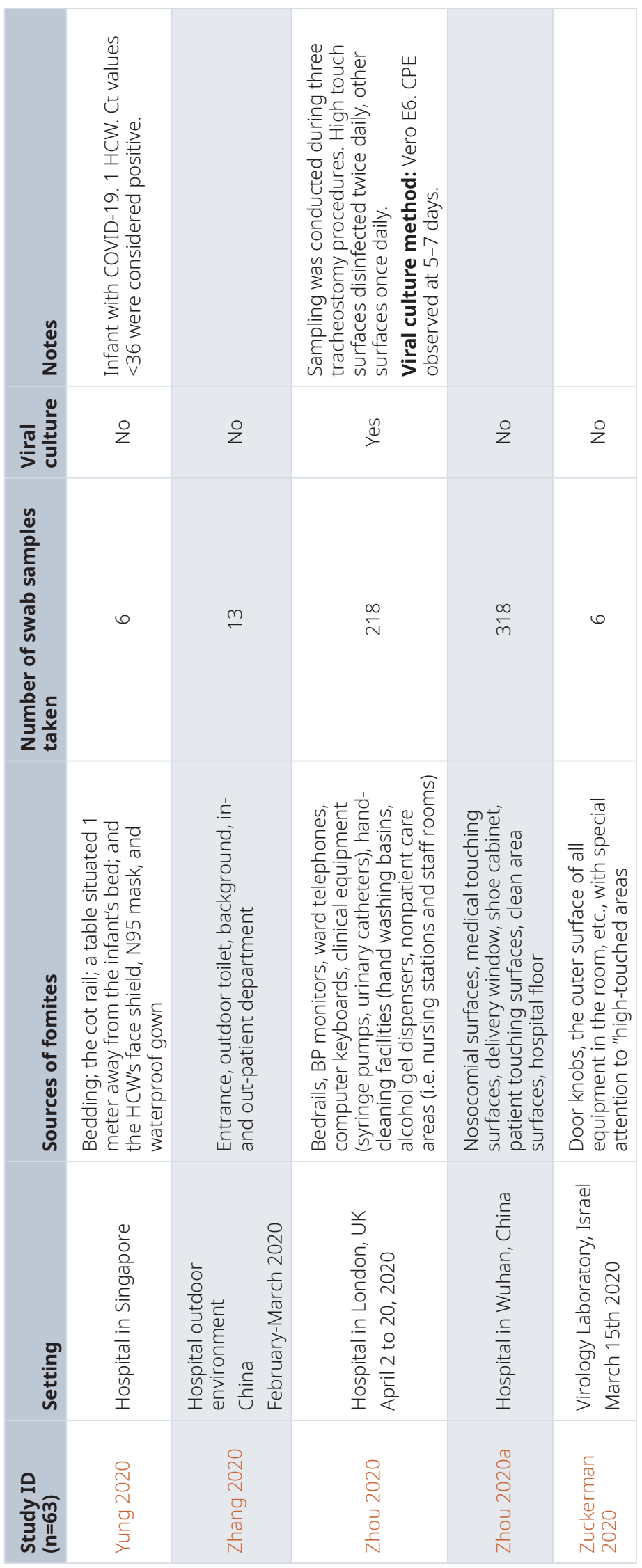




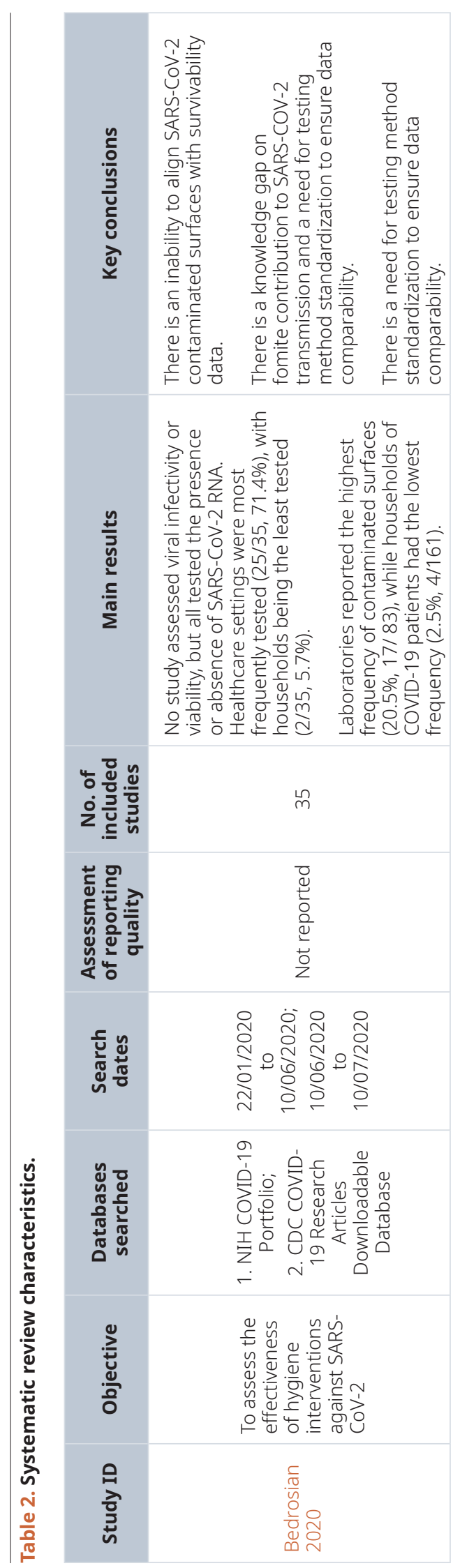




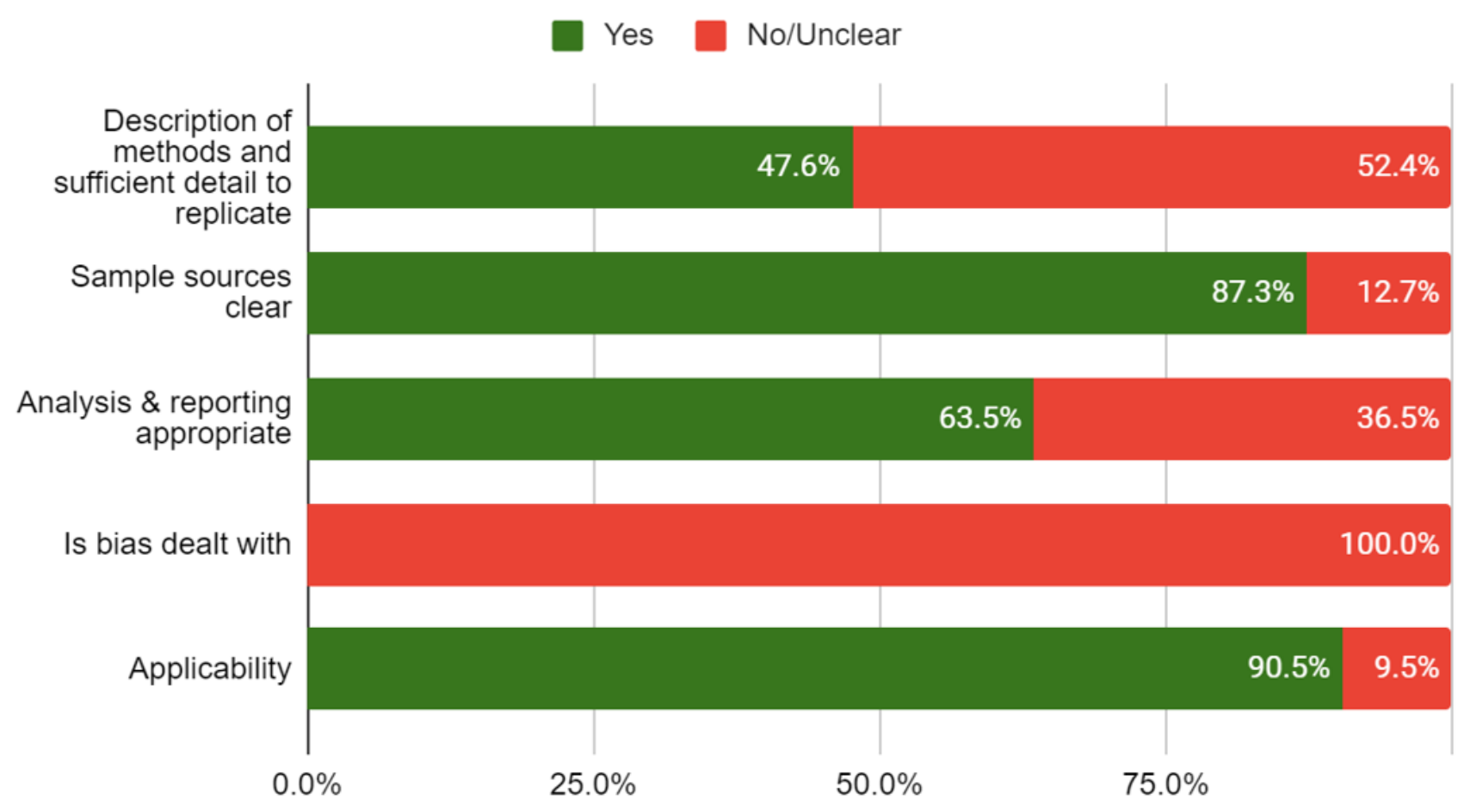

Figure 2. Risk of bias ( $n=63$ primary studies).

(20.6\%) reported cycle thresholds $(\mathrm{Ct})$ for test positivity: $\leq 40$ (8 studies); $\leq 43$ (1 study); <35 (1 study); <36 (1 study); <37 ( 1 study) and $<38$ ( 1 study).

\section{Frequency of SARS-CoV-2 positive test}

All studies reported data on the frequency of positive tests (Table 5). (Figure 3 shows the graphical representation of these frequencies.) The frequency of positive SARS-CoV-2 tests across 51 studies (via RT-PCR) ranged from $0.5 \%$ to $75 \% ; 12$ studies $(19 \%)$ reported no positive tests. The highest frequency of positive tests was found in residential isolation rooms. Of the three studies conducted in ICU [Escudero 2000, Jin 2000, Ong 2000 and Seyedmehdi 2000], two reported positive test results (11.7\% and 40\%). All the four studies [Lei 2000, Ma 2000, Ge 2020, Jerry 2000] conducted in both ICU and general wards reported positive tests: $5 \%, 5.4 \%, 14.3 \%$ and $16.3 \%$, respectively. One of the three laboratory studies [Bloise 2000] reported frequency of $18.2 \%$; a second study [Lv 2020] reported no positive test with the conventional RT-PCR tests but reported $21.3 \%$ positivity with droplet digital PCR (ddPCR) tests; the third study [Zuckerman 2020] reported no positive tests. In a cross-sectional study of SARS-CoV-2 positive subjects confined to their cabins in a cruise ship [Suzuki 2020], the frequency of positive test was $9.7 \%$ (58/601); no positive test was detected in the non-case cabins. In one study of home quarantined subjects [Maestre 2020], 46.2\% (12/26) of samples were positive for SARS-CoV-2 at two months (one month after the resolution of symptoms). In another study of two hospital patients who were SARS-CoV-2 positive [Shin 2020], no positive samples were detected after 41 days following weekly disinfection. One study conducted in a high-prevalence community setting [Döhla 2020] reported no significant association in the frequencies of positive tests between human and environmental samples $(\mathrm{p}=0.76)$. In all four before and after studies, there was a substantial reduction in the frequency of positive tests after surface disinfection.

\section{Viral load and concentration}

A total of 17 studies reported data on viral concentration (Table 5); the units of measure used to report this data varied across the studies and included genomic copies/swab (4 studies), genomic copies $/ \mathrm{cm}^{2}$ (4 studies), genomic copies $/ \mathrm{mL}$ (4 studies), and 1 study each for mean concentration, viruses $/ \mathrm{cm}^{2}$, genomic units $/ \mathrm{m}^{2}$, genomic copies/sample and RNA copies. We found it impossible to make any comparisons across the studies because of the heterogeneity in units of measurement.

\section{Cycle thresholds}

A total of 28 studies (44.4\%) reported data in $\mathrm{Ct}$ with values ranging from 20.4 to 44.1 (Table 5). One study of ICU patients [Razzini 2020] reporting positive rates of $24.3 \%$ (9/34) had the lowest range of $\mathrm{Ct}(21.5-24)$, while another study of ICU and isolation ward patients [Lei 2020] reporting positive rates of $5 \%$ (9/182) had the highest range of $\mathrm{Ct}$ (38.6-44); in both studies, the $\mathrm{Ct}$ for positivity was $\leq 40$.

\section{Viral culture}

Of the 11 studies that planned to perform viral culture, only two (18.2\%) reported $\mathrm{Ct}$ values that could act as prompts to undertake viral isolation (Table 6). Only two studies 
Table 3. Studies sample collection characteristics.

\begin{tabular}{|c|c|c|}
\hline Study ID & $\begin{array}{l}\text { Frequency of } \\
\text { sample collection }\end{array}$ & Timing of sample collection \\
\hline Abrahão 2020 & Not specified & Not specified \\
\hline Akter 2020 & NA & N/A \\
\hline Amoah 2020 & Twice & Unspecified \\
\hline Ben-Shmuel 2020 & Not specified & Not specified \\
\hline Bloise 2020 & Not specified & Not specified \\
\hline Cheng 2020 & Not specified & Not specified \\
\hline Cheng 2020a & Once & Before daily disinfection \\
\hline Chia 2020 & Not specified & Not specified \\
\hline Colaneri 2020 & Not specified & Not specified \\
\hline Colaneri 2020a & Once & After disinfection \\
\hline D’Accolti 2020 & Not specified & After disinfection \\
\hline Declementi 2020 & Twice & After disinfection \\
\hline Ding 2020 & Not specified & Before disinfection \\
\hline Döhla 2020 & Not specified & Not specified \\
\hline Escudero 2020 & Not specified & Not specified \\
\hline Feng 2020 & Not specified & Not specified \\
\hline Fernández-de-Mera 2020 & Not specified & Not specified \\
\hline Ge 2020 & 1 to 3 times & Not specified \\
\hline Guo 2020 & Not specified & Not specified \\
\hline Harvey 2020 & $\begin{array}{l}\text { Twice: Pilot phase } \\
\text { and full-scale phase }\end{array}$ & N/A \\
\hline Hu 2020 & Not specified & Not specified \\
\hline Hu 2020a & 3 times & $4 \mathrm{~h}$ after case confirmation \\
\hline Jerry 2020 & Not specified & $4 \mathrm{~h}$ after disinfection \\
\hline Jiang 2020 & Not specified & Not specified \\
\hline Jiang 2020a & Not specified & Before disinfection \\
\hline Jin 2020 & Not specified & $2 \mathrm{~h}$ after disinfection \\
\hline Kim 2020 & Not specified & Not specified \\
\hline Lee 2020 & Not specified & $\begin{array}{l}\text { After disinfection (hospital) } \\
\text { Before disinfection (mass facilities) }\end{array}$ \\
\hline Lei 2020 & Twice & Before disinfection \\
\hline Lui 2020 & N/A & N/A \\
\hline LV 2020 & Not specified & Not specified \\
\hline Ma 2020 & Not specified & Not specified \\
\hline Maestre 2020 & Not specified & Not specified \\
\hline Marshall 2020 & End of work shift & Before disinfection \\
\hline Moore 2020 & Not specified & Not specified \\
\hline
\end{tabular}




\begin{tabular}{|c|c|c|}
\hline Study ID & $\begin{array}{l}\text { Frequency of } \\
\text { sample collection }\end{array}$ & Timing of sample collection \\
\hline Nakamura 2020 & Not specified & After disinfection \\
\hline Nelson 2020 & Not specified & Not specified \\
\hline Ong 2020 & $\begin{array}{l}5 \text { separate time } \\
\text { points }\end{array}$ & Before disinfection \\
\hline Ong 2020a & $\begin{array}{l}5 \text { days over a } \\
\text { 2-week period }\end{array}$ & Before and after (33.3\%:66.7\%) \\
\hline Ong 2020b & Not specified & Not specified \\
\hline Pasquarella 2020 & Once & After disinfection \\
\hline Peyrony 2020 & Not specified & Not specified \\
\hline Piana 2020 & Not specified & Before disinfection \\
\hline Razzini 2020 & Not specified & Before disinfection \\
\hline Ryu 2020 & Not specified & Not specified \\
\hline Santarpia 2020 & Not specified & Not specified \\
\hline Seyedmehdi 2020 & Not specified & Not specified \\
\hline Shin 2020 & Twice daily & After disinfection (4 days) \\
\hline Suzuki 2020 & Not specified & Before disinfection \\
\hline Wang 2020 & Not specified & Not specified \\
\hline Wang 2020a & Not specified & Not specified \\
\hline Wee 2020 & Not specified & Before disinfection \\
\hline Wei 2020 & Not specified & After disinfection \\
\hline Wei 2020a & Not specified & Before disinfection \\
\hline Wong 2020 & Not specified & Before and after (50\%:50\%) \\
\hline Wu 2020 & Not specified & Before disinfection \\
\hline Ye 2020 & $\begin{array}{l}\text { Three sets over a } \\
\text { 20-day period }\end{array}$ & Not specified \\
\hline Yuan 2020 & Not specified & After disinfection \\
\hline Yung 2020 & Not specified & Not specified \\
\hline Zhang 2020 & Not specified & Not specified \\
\hline Zhou 2020 & Not specified & Not specified \\
\hline Zhou 2020a & Not specified & Not specified \\
\hline Zuckerman 2020 & Not specified & Before disinfection \\
\hline
\end{tabular}

provided information on the timing of sample collection for viral culture but were missing key details with respect to collection related to the timing of the onset of symptoms of the patients with respect to the collection and timing. One study of subjects in a cruise ship [Suzuki 2020] reported collecting samples for viral culture from 1-17 days after the cabin was vacated on a cruise ship and at least 17 days after the quarantining to cabins was ordered and 8 days after the first cabin cleaning, while another study of patients in residential isolation [Santarpia 2020] reported collecting the samples on "days 5-9" or "day 10 " of occupancy at a medical centre or quarantine unit, all of whom were evacuated from the same cruise ship reported previously and would have been at least 2 weeks from the last day of quarantine [Suzuki 2020]. The incubation period ranged from 4-7 days and there were subtle differences in the culture media used across the studies (Table 6). None of the studies reported success with viral culture despite positive RT-PCR detection tests. There were methodological issues with the techniques employed for viral culture across the studies (see Table 6). 
Table 4. Quality of included studies.

\begin{tabular}{|c|c|c|c|c|c|}
\hline Study & $\begin{array}{l}\text { Description of } \\
\text { methods and sufficient } \\
\text { detail to replicate }\end{array}$ & $\begin{array}{l}\text { Sample } \\
\text { sources } \\
\text { clear }\end{array}$ & $\begin{array}{l}\text { Analysis \& } \\
\text { reporting } \\
\text { appropriate }\end{array}$ & $\begin{array}{l}\text { Is bias } \\
\text { dealt with }\end{array}$ & Applicability \\
\hline Abrahão 2020 & Unclear & Yes & Yes & Unclear & Yes \\
\hline Akter 2020 & Yes & Yes & Yes & Unclear & Yes \\
\hline Amoah 2020 & Unclear & Yes & Yes & No & Yes \\
\hline Bloise 2020 & Unclear & Yes & Unclear & No & Yes \\
\hline Ben-Shmuel 2020 & Yes & Yes & Yes & Unclear & Yes \\
\hline Cheng 2020 & Unclear & Yes & Yes & No & Yes \\
\hline Cheng 2020a & Unclear & Yes & Yes & Unclear & Yes \\
\hline Chia 2020 & No & Yes & Yes & Unclear & Yes \\
\hline Colaneri 2020 & Unclear & Unclear & Unclear & Unclear & Unclear \\
\hline Colaneri 2020a & Yes & Yes & Unclear & Unclear & Yes \\
\hline D'Accolti 2020 & Yes & Yes & No & No & Yes \\
\hline Declementi 2020 & Unclear & Yes & Yes & Unclear & Yes \\
\hline Ding 2020 & Yes & Yes & Yes & Unclear & Yes \\
\hline Döhla 2020 & Unclear & Unclear & Yes & No & Yes \\
\hline Escudero 2020 & Yes & Yes & Yes & Unclear & Yes \\
\hline Feng 2020 & Unclear & Yes & Unclear & Unclear & Yes \\
\hline Fernández-de-Mera 2020 & Unclear & Yes & Unclear & No & Yes \\
\hline Ge 2020 & Unclear & Yes & Unclear & Unclear & Yes \\
\hline Guo 2020 & Unclear & Yes & Unclear & No & Unclear \\
\hline Harvey 2020 & Yes & Yes & Yes & Unclear & Yes \\
\hline Hu 2020 & No & Unclear & No & No & Unclear \\
\hline Hu 2020a & Unclear & Yes & Yes & Unclear & Yes \\
\hline Jerry 2020 & Yes & Yes & Yes & Unclear & Yes \\
\hline Jiang 2020 & Yes & Yes & Unclear & Unclear & Yes \\
\hline Jiang 2020a & Unclear & Yes & Yes & No & Yes \\
\hline Jin 2020 & Yes & Yes & Unclear & Unclear & Yes \\
\hline Kim 2020 & Yes & Yes & Unclear & Unclear & Yes \\
\hline Lee 2020 & Unclear & Yes & Yes & Unclear & Yes \\
\hline Lei 2020 & Unclear & Yes & Yes & No & Yes \\
\hline Lui 2020 & Unclear & Unclear & Unclear & Unclear & Unclear \\
\hline LV 2020 & Yes & Yes & Unclear & No & Yes \\
\hline Ma 2020 & No & Unclear & Yes & No & Yes \\
\hline Maestre 2020 & Yes & Yes & Yes & Unclear & Yes \\
\hline Marshall 2020 & Unclear & Yes & Yes & Unclear & Yes \\
\hline Moore 2020 & Yes & Yes & Yes & Unclear & Yes \\
\hline Nakamura 2020 & Yes & Yes & Yes & Unclear & Yes \\
\hline
\end{tabular}




\begin{tabular}{|c|c|c|c|c|c|}
\hline Study & $\begin{array}{l}\text { Description of } \\
\text { methods and sufficient } \\
\text { detail to replicate }\end{array}$ & $\begin{array}{l}\text { Sample } \\
\text { sources } \\
\text { clear }\end{array}$ & $\begin{array}{l}\text { Analysis \& } \\
\text { reporting } \\
\text { appropriate }\end{array}$ & $\begin{array}{l}\text { Is bias } \\
\text { dealt with }\end{array}$ & Applicability \\
\hline Nelson 2020 & Unclear & Yes & Unclear & Unclear & Yes \\
\hline Ong 2020 & Yes & Yes & Yes & No & Yes \\
\hline Ong 2020a & Unclear & Yes & Yes & Unclear & Yes \\
\hline Ong 2020b & Unclear & Yes & Unclear & Unclear & Yes \\
\hline Pasquarella 2020 & Unclear & Yes & Unclear & Unclear & Yes \\
\hline Peyrony 2020 & Yes & Yes & Yes & Unclear & Yes \\
\hline Piana 2020 & Yes & Yes & Yes & Unclear & Yes \\
\hline Razzini 2020 & Yes & Yes & Yes & Unclear & Yes \\
\hline Ryu 2020 & Yes & Yes & Yes & Unclear & Yes \\
\hline Santarpia 2020 & Yes & Yes & Unclear & Unclear & Yes \\
\hline Seyedmehdi 2020 & No & Unclear & Unclear & No & Unclear \\
\hline Shin 2020 & Unclear & Unclear & Yes & Unclear & Yes \\
\hline Suzuki 2020 & Yes & Yes & Unclear & Unclear & Yes \\
\hline Wee 2020 & Yes & Yes & Yes & Unclear & Yes \\
\hline Wei 2020 & Yes & Yes & Unclear & Unclear & Yes \\
\hline Wei 2020a & Unclear & Yes & Yes & Unclear & Yes \\
\hline Wang 2020 & Yes & Yes & Yes & Unclear & Yes \\
\hline Wang 2020a & Unclear & Yes & Yes & Unclear & Yes \\
\hline Wong 2020 & Unclear & Yes & Yes & Unclear & Yes \\
\hline Wu 2020 & Unclear & Yes & Unclear & Unclear & Yes \\
\hline Ye 2020 & Unclear & Yes & Yes & Unclear & Yes \\
\hline Yuan 2020 & Yes & Yes & Yes & Unclear & Yes \\
\hline Yung 2020 & Unclear & Yes & Yes & No & Yes \\
\hline Zhang 2020 & Unclear & Unclear & Unclear & Unclear & Unclear \\
\hline Zhou 2020 & Yes & Yes & Yes & Unclear & Yes \\
\hline Zhou 2020a & Unclear & Yes & Yes & Unclear & Yes \\
\hline \multirow[t]{4}{*}{ Zuckerman 2020} & Yes & Yes & Yes & Unclear & Yes \\
\hline & 30 & 55 & 40 & 0 & 57 \\
\hline & 63 & 63 & 63 & 63 & 63 \\
\hline & Yes & $\begin{array}{l}\text { No/ } \\
\text { Unclear }\end{array}$ & & & \\
\hline $\begin{array}{l}\text { Description of methods and } \\
\text { sufficient detail to replicate }\end{array}$ & $47.6 \%$ & $52.4 \%$ & & & \\
\hline Sample sources clear & $87.3 \%$ & $12.7 \%$ & & & \\
\hline $\begin{array}{l}\text { Analysis \& reporting } \\
\text { appropriate }\end{array}$ & $63.5 \%$ & $36.5 \%$ & & & \\
\hline Is bias dealt with & $0.0 \%$ & $100.0 \%$ & & & \\
\hline Applicability & $90.5 \%$ & $9.5 \%$ & & & \\
\hline
\end{tabular}




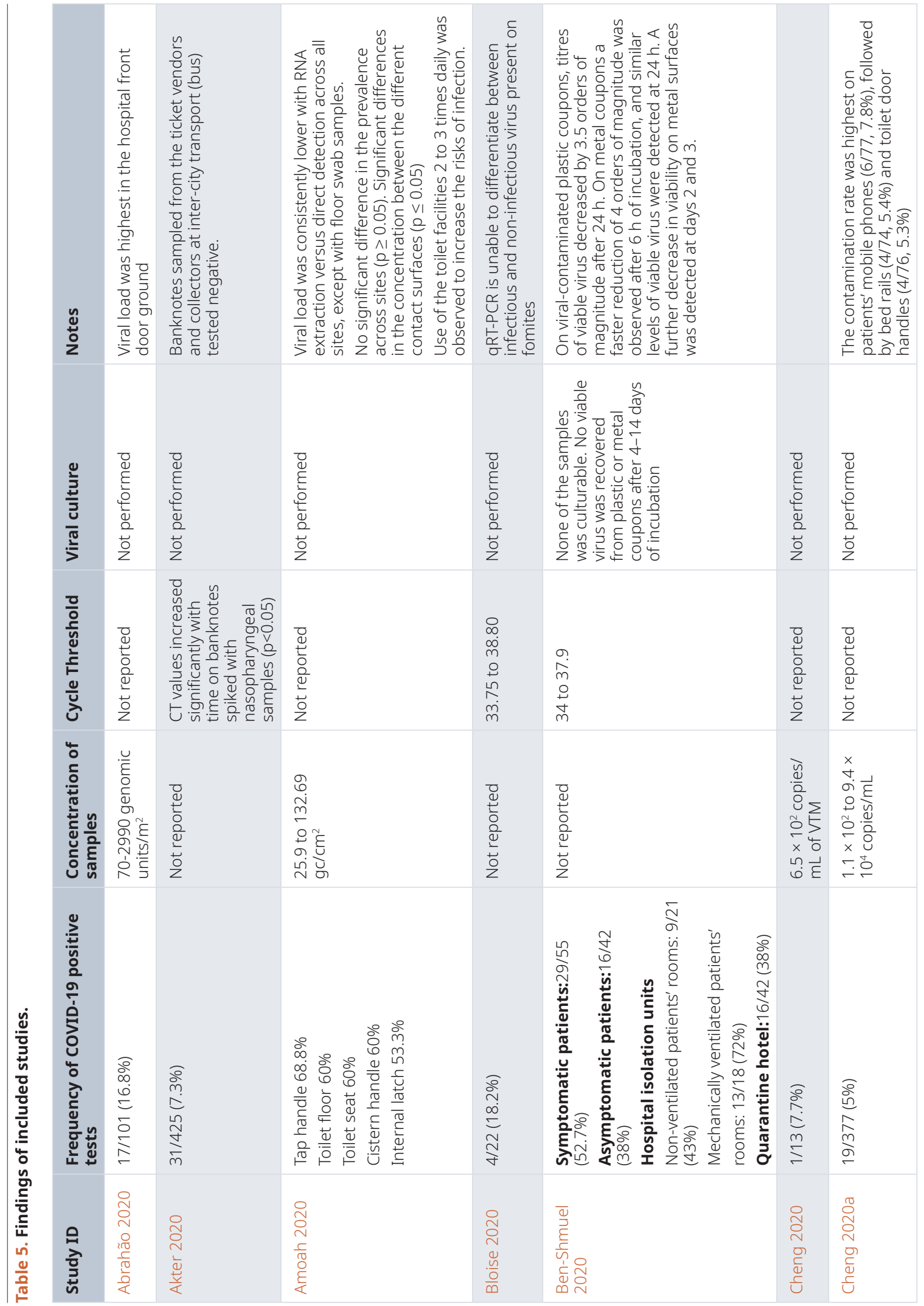




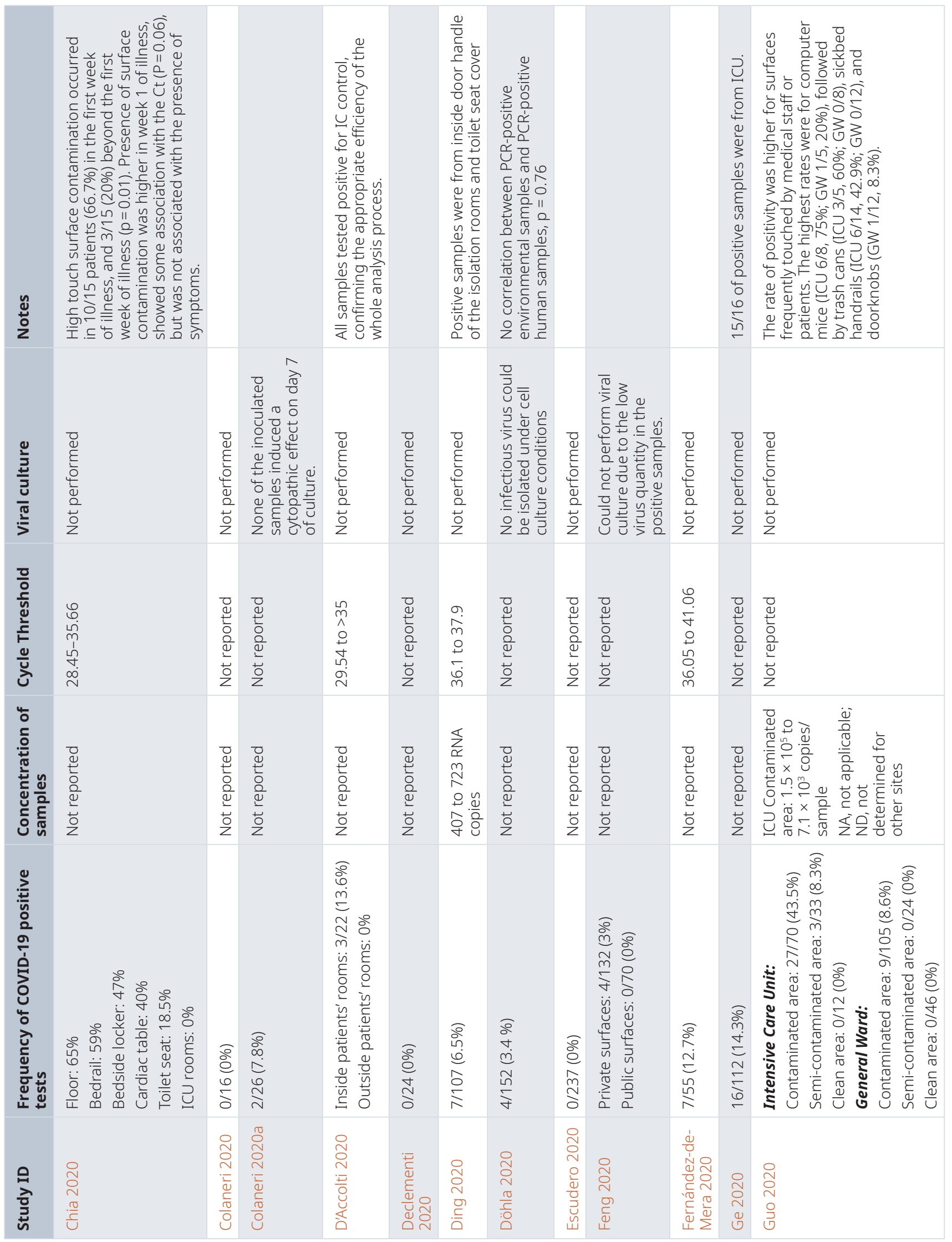




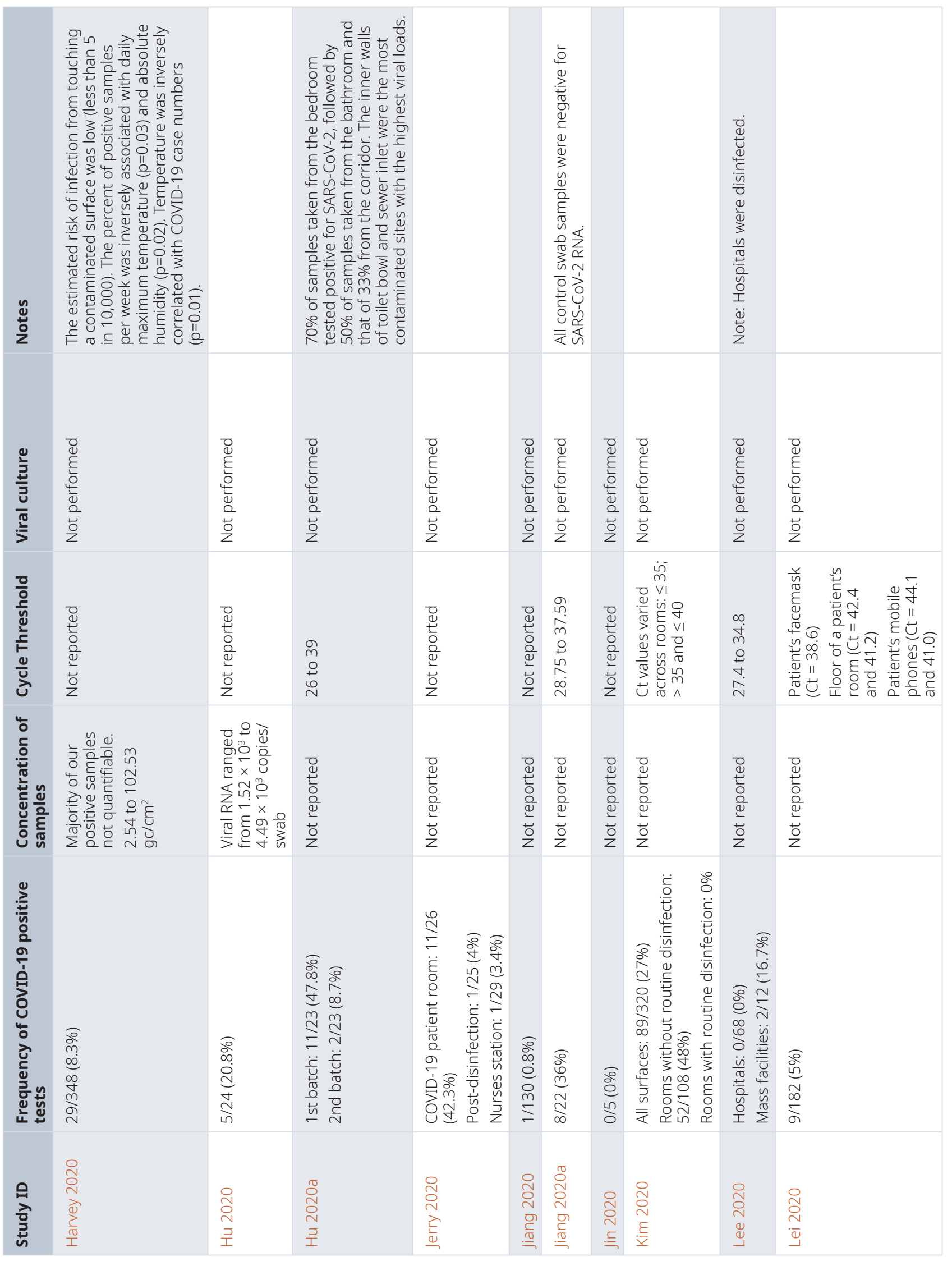




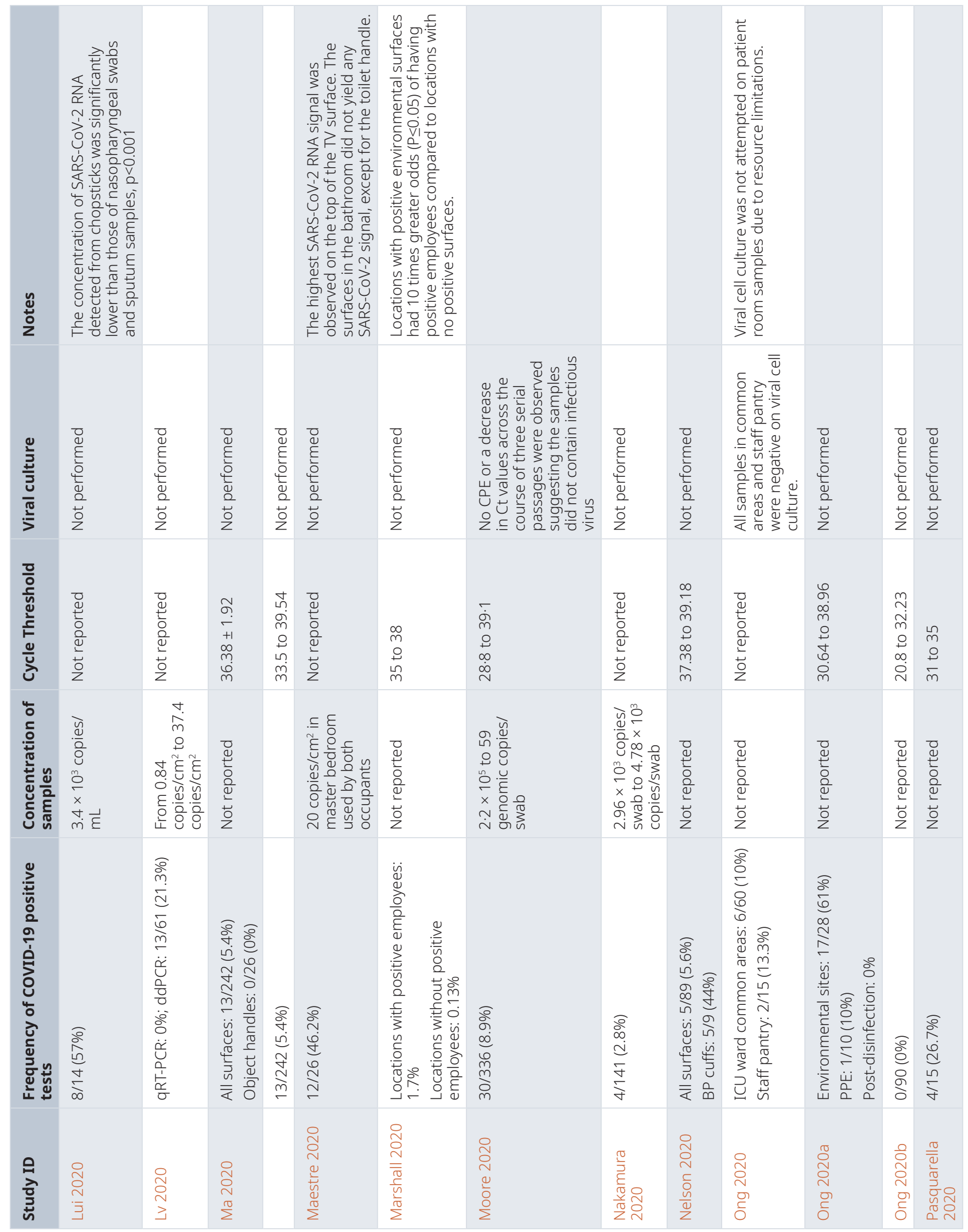




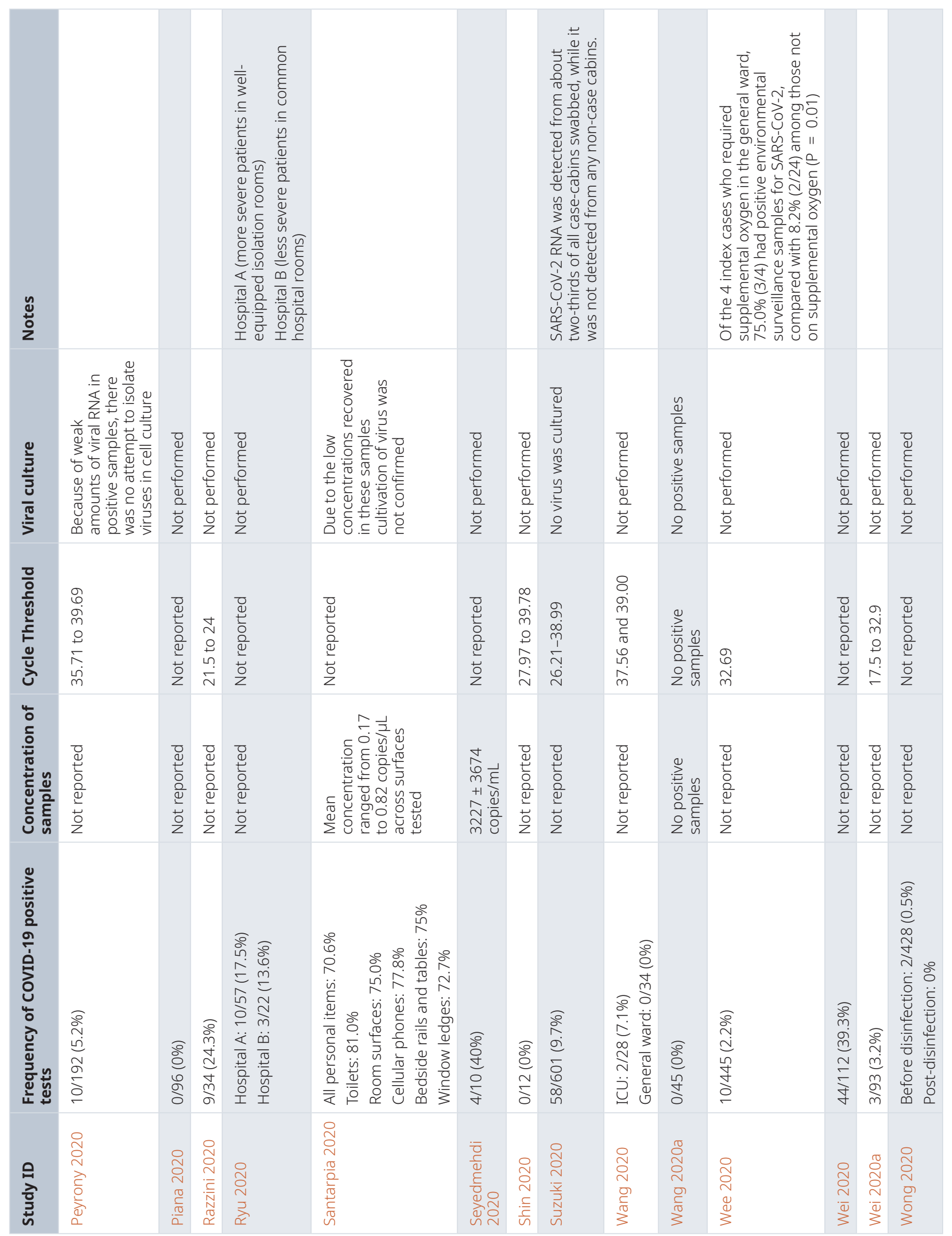




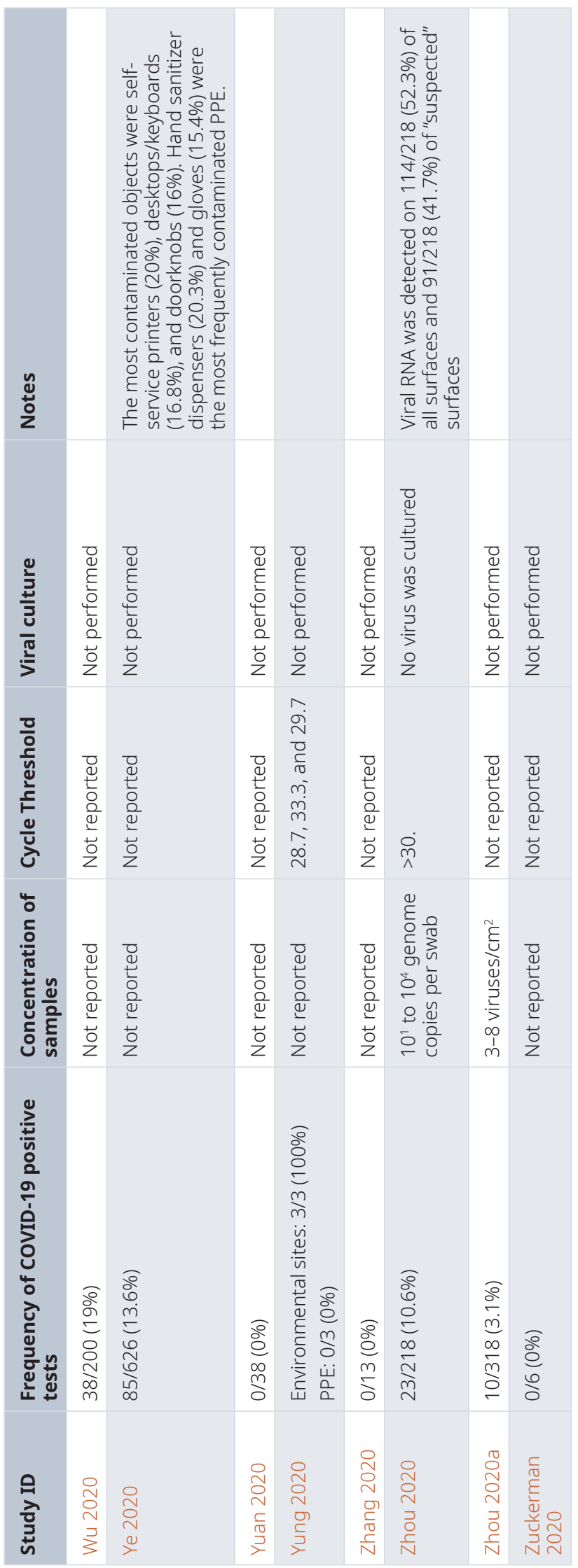




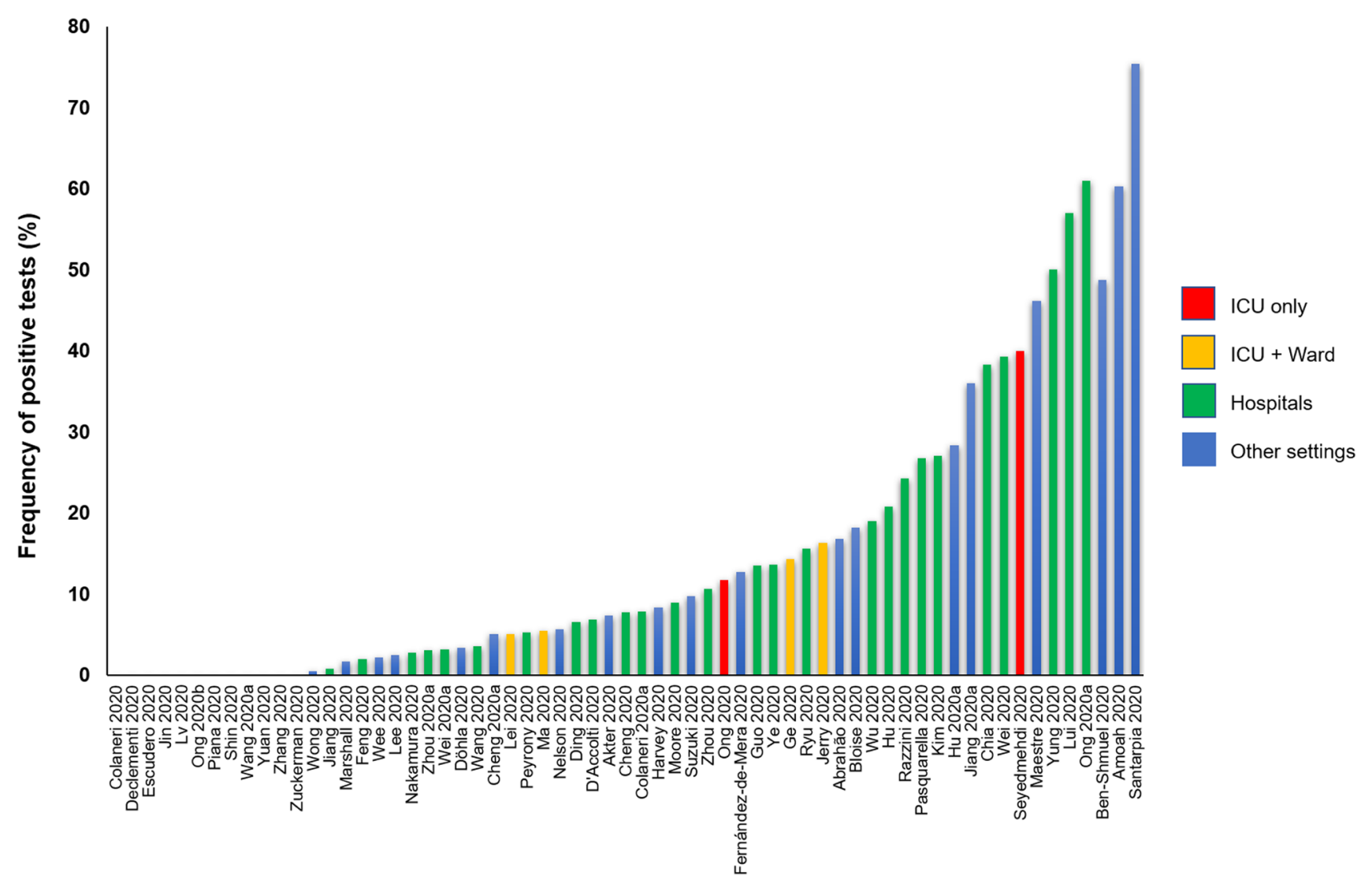

Figure 3. Rates of positive SARS-Cov-2 tests in studies assessing fomite transmission.

\section{Discussion}

We found 63 primary studies investigating the role of fomites in SARS-CoV-2 transmission. The results of the majority of these studies show that SARS-CoV-2 RNA can be frequently detected on surfaces in both healthcare and nonhealthcare settings. However, there were no positive culture results for studies that attempted to culture for viable virus. There is a wide variation in study setting and designs across studies, and the overall quality of published studies is low to moderate. The heterogeneity in study design and methodology makes it difficult to compare results across studies. The results of the systematic review $(n=35)$ [Bedrosian 2020] showed that surface contamination was greatest in laboratories and least in households; however, none of the included studies addressed viral infectivity. The review authors did not assess the reporting quality of the primary studies and the search periods are now outdated.

The inability to culture the virus despite positive PCR detection tests suggests that SARS-CoV-2 RNA is more stable (and likely found in greater concentrations) on fomites than infective SARS-CoV-2 virus ${ }^{11}$. Factors known to affect the ability of fomites to serve as transmitters of respiratory viruses include the rate of decay of the virus on the surface and on the hands, the virus transfer rate (surface to hand, and hand to face), the frequency of touch between the hands and face, the dose-response curve of the virus, temperature and humidity, amongst others ${ }^{12}$.

The substantial reduction in positive detection rates before and after studies (and in some ICU settings) suggests that good hygiene procedures can minimise the risk of surface contamination. The inconsistency in describing a priori $\mathrm{Ct}$ values across the studies, coupled with the wide range in actual $\mathrm{Ct}$ values, suggests that the reported positive SARS-CoV-2 RNA detection rates are markers of previous viral presence from non-viable virus.

In a systematic review assessing the role of fomites in virus transmission in the Middle East Respiratory Syndrome (MERS) $)^{13}$, the authors reported possible evidence of fomite contamination but the evidence for fomite transmission was anecdotal. Our review findings are consistent with these observations. In an observational study of four hospitalised patients with $\mathrm{MERS}^{14}$, there was positive viral culture from fomites including bed sheets, bed rails, intravenous fluid hangers, and radiograph devices. In contrast to that study, published research on SARS-CoV-2 shows no evidence of positive viral culture 


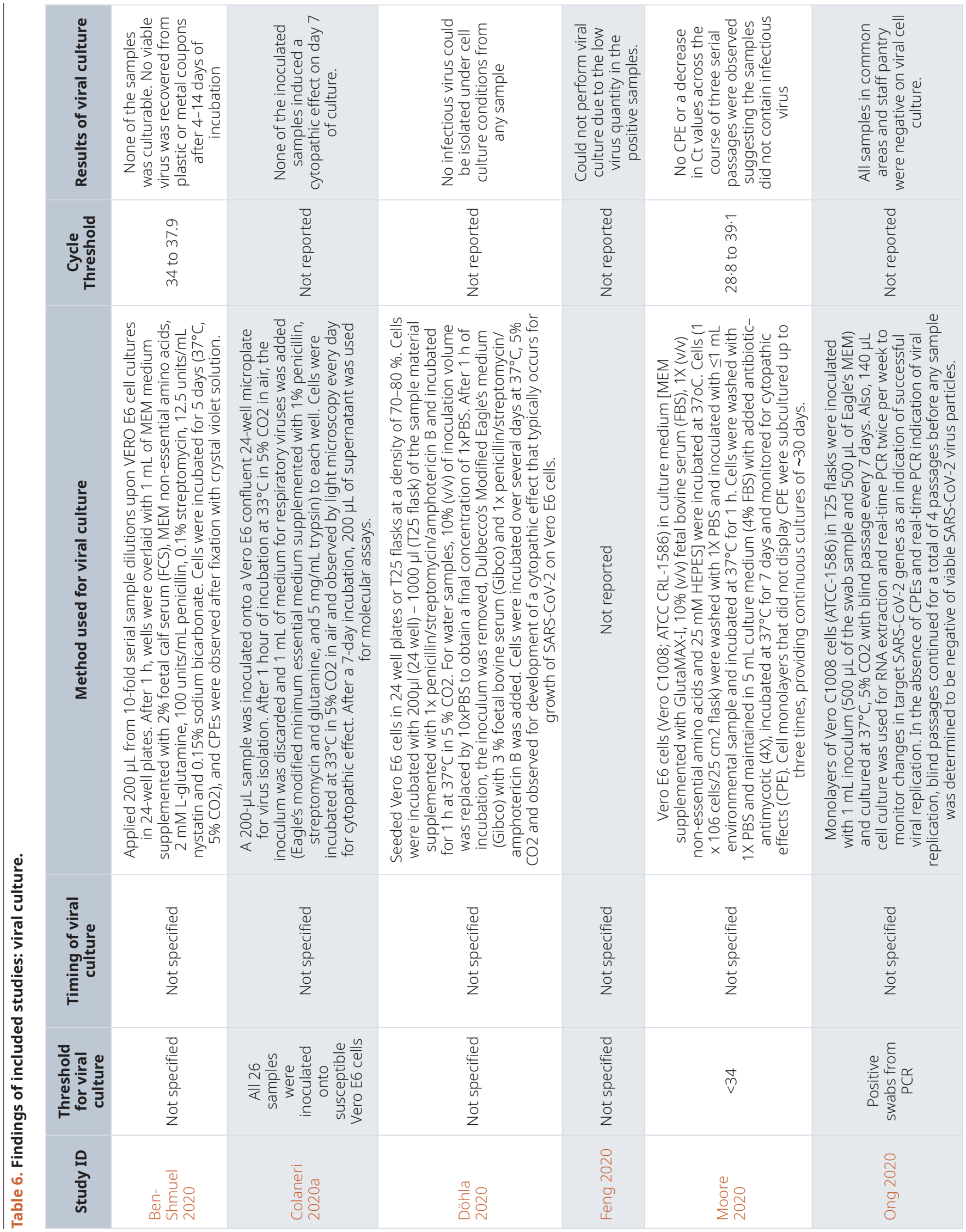




\begin{tabular}{|c|c|c|c|c|c|}
\hline 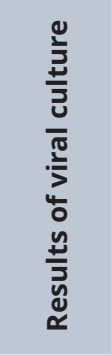 & 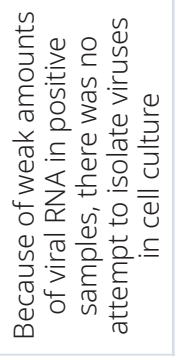 & 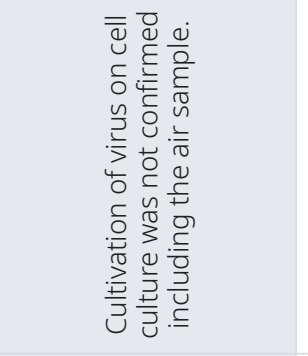 & 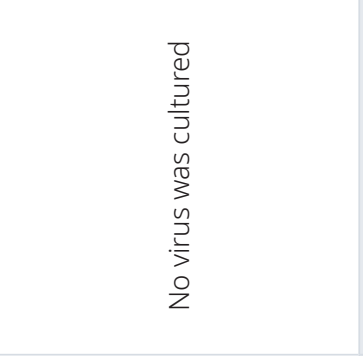 & 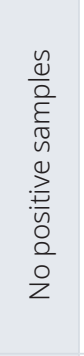 & 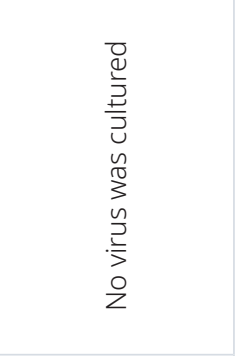 \\
\hline 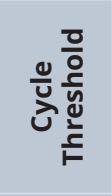 & 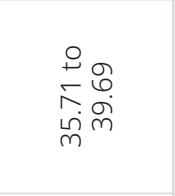 & 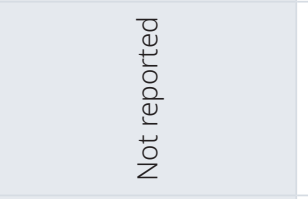 & 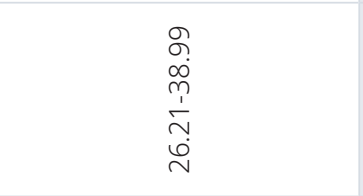 & 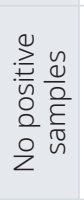 & ஜ் \\
\hline 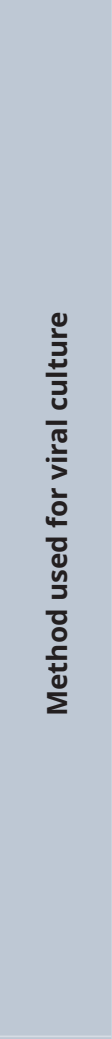 & 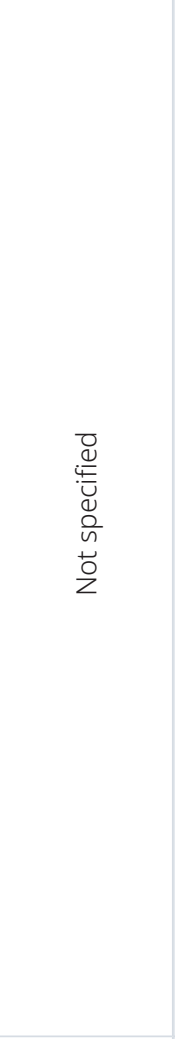 & 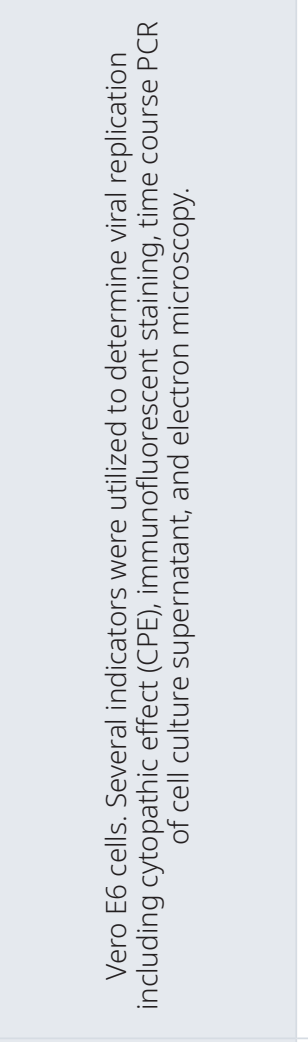 & 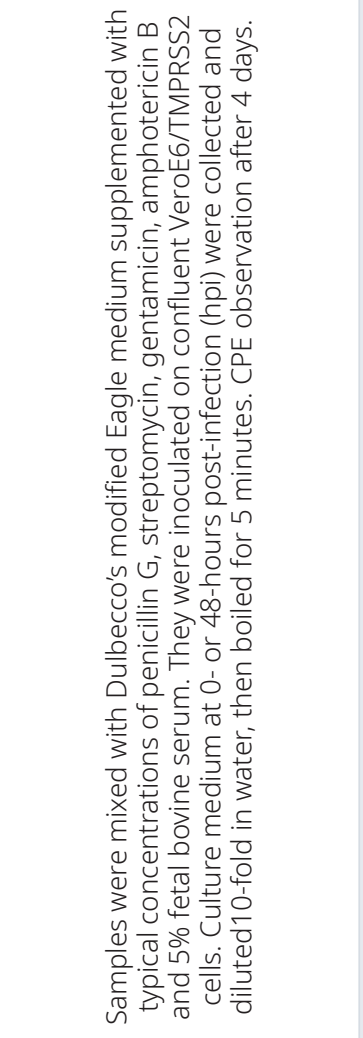 & 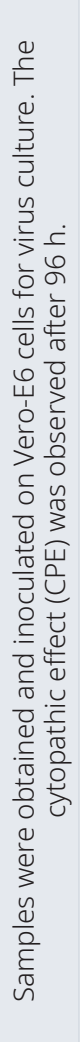 & 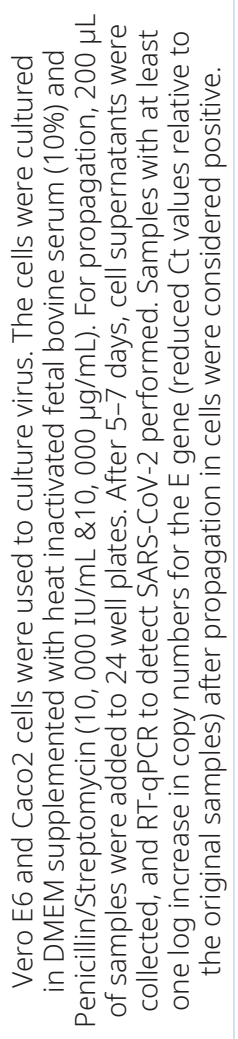 \\
\hline 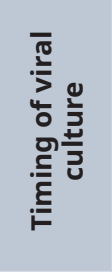 & 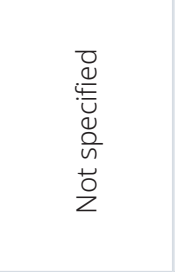 & 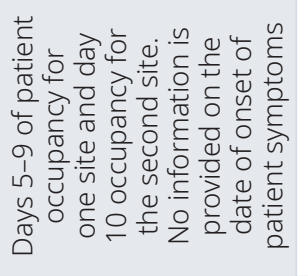 & 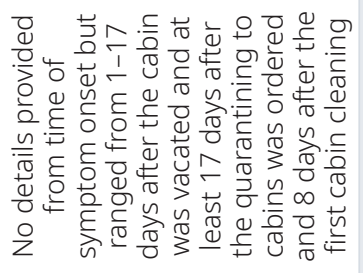 & 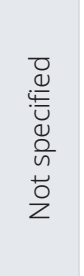 & 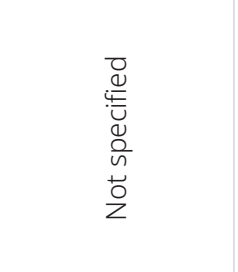 \\
\hline 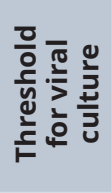 & 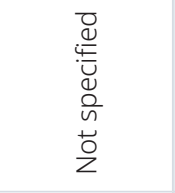 & 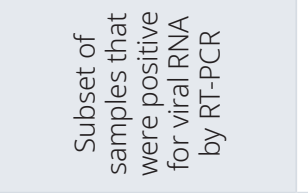 & 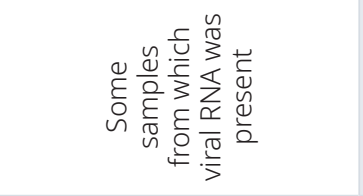 & 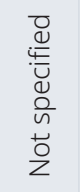 & 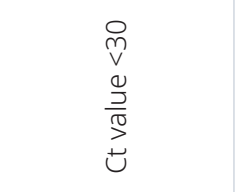 \\
\hline 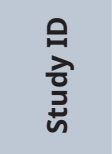 & $\begin{array}{l}\text { 이 } \\
\text { đర్ల } \\
\alpha\end{array}$ & 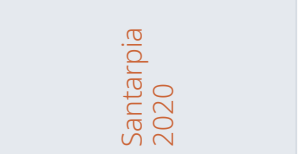 & ㄱ & 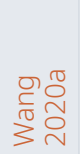 & 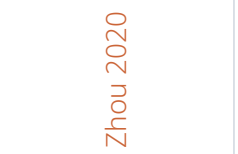 \\
\hline
\end{tabular}


to date. Our review findings support several national and international guidelines recommending good hygiene practices to reduce the spread of SARS-CoV-2 ${ }^{15-17}$.

We identified one non-peer-reviewed (pre-print) systematic review that assessed SARS-CoV-2 contamination in fomites ${ }^{18}$. The authors concluded that the quality of measurements was poor, and the reliability of the data is uncertain. Our findings are consistent with these. Compared to that review, we searched more databases, included more than twice the number of included studies, and accounted for the reporting quality of included studies.

Although there has been much research into fomite transmission of SARS-CoV-2, much uncertainty remains, and it is difficult to draw meaningful conclusions. Firstly, the variation in $\mathrm{Ct}$ across the studies suggests that there is no standardized threshold for detection of SARS-CoV-2 RNA. Some studies have shown that lower $\mathrm{Ct}$ correlates with higher genomic load ${ }^{19}$.

The studies included in this review used $\mathrm{Ct}$ of $<35$ to $<43$; these threshold values indicate that some of the positive tests reported in the studies may be misleading. Future research aimed at establishing internationally accepted $\mathrm{Ct}$ values should be considered a priority. The discrepancies in units of measurements for viral load and/or concentration also creates confusion. Therefore, standardized checklists for reporting of studies investigating SARS-CoV-2 transmission should be developed, including mandatory publishing of protocols, including the timing of the collection of any environmental specimens with respect to patient symptom onset. Looking for viable virus long after a patient has developed a significant innate and adaptive immunologic response will consistently yield negative results.

That all 11 culture studies failed to isolate the virus with significant fundamental methodological flaws indicates that the threshold for transmissibility from contaminated surfaces is unknown and more rigorous and carefully orchestrated studies are required before any conclusions may be drawn. One factor likely relates to the timing of sample collection after the onset of infection. Two studies reported the timeframe for sample collection but without precision while nine did not report any timelines. The mean incubation period of SARS-CoV-2 is 5-6 days ${ }^{2}$; therefore, sample collection within the first few days of infection onset is likely to yield greater viral RNA load and result in better infectivity and culture results. Future studies should endeavour to collect surface samples of likely contaminated surfaces and medical equipment within useful timeframes and should also report this variable with their results.

As reported in the results, findings from one study [Lv 2020] showed that detection rates were different when qRT-PCR was compared with ddPCR. Interestingly, the authors of another included study [Bloise 2020] concluded that qRT-PCR is unable to differentiate between infectious and non-infectious viruses. Therefore, the use of RT-PCR as the gold standard for detection of SARS-CoV-2 requires further research. The positive findings from the before and after studies show that good hygiene procedures should continue to be a cornerstone for the management of SARS-CoV-2 and other communicable diseases.

\section{Strengths and limitations}

To our knowledge, this is the most comprehensive review to date that evaluates the role of fomites in SARS-CoV-2 transmission. We extensively searched the literature for published studies and included studies that are yet to undergo peer review. We also accounted for the quality of the studies and have presented summary data for some subgroups where possible. However, we recognize several limitations. We may not have identified all published studies investigating the role of fomites; indeed, several other studies may have been published after the last search date for this review. Heterogeneity due to variations in study designs and lack of uniformity in measurement metrics prevent us from statistically combining data across studies and limits the validity and applicability of the review results.

\section{Conclusion}

The evidence from published research suggests that SARS-CoV-2 RNA can be readily detected on surfaces and fomites. There is no evidence of viral infectivity or transmissibility via fomites to date but no studies to date have been found to be methodologically robust and of high enough quality to even adequately address the question. Good hygienic practices appear to reduce the incidence of surface contamination. Published studies are heterogeneous in design, methodology and viral reporting metrics and there are flaws in the reporting quality. Standardized guidelines for the design and reporting of research on fomite transmission should now be a priority.

\section{Data availability}

Underlying data

All data underlying the results are available as part of the article and no additional source data are required.

\section{Extended data}

Figshare: Extended data: SARS-CoV-2 and the Role of Fomite Transmission: A Systematic Review, https://doi.org/10.6084/ m9.figshare.14247113.v19.

This project contains the following extended data:

- $\quad$ Appendix 1: Protocol

- $\quad$ Appendix 2: Search Strategy

- $\quad$ Appendix 3: List of excluded studies

- $\quad$ Appendix 4: References to included studies

Reporting guidelines

Figshare: PRISMA checklist for 'SARS-CoV-2 and the Role of Fomite Transmission: A Systematic Review', https://doi. org/10.6084/m9.figshare.14247113.v19.

Data are available under the terms of the Creative Commons Attribution 4.0 International license (CC-BY 4.0). 


\section{Acknowledgements}

This work was commissioned and paid for by the World Health Organization (WHO). Copyright on the original work on which this article is based belongs to WHO. The authors have been given permission to publish this article. The author(s) alone is/are responsible for the views expressed in the publication. They do not necessarily represent views, decisions, or policies of the World Health Organization.
1. World Health Organization: WHO Coronavirus Disease (COVID-19) Dashboard. [Accessed 18/01/2021].

Reference Source

2. World Health Organization: Transmission of SARS-CoV-2: implications for infection prevention precautions. [Accessed 16/01/2021]. Reference Source

3. World Health Organization: Modes of transmission of virus causing COVID-19: implications for IPC precaution recommendations. [Accessed 16/01/2021]. Reference Source

4. Kramer A, Schwebke I, Kampf G: How long do nosocomial pathogens persist on inanimate surfaces? A systematic review. BMC Infect Dis. 2006; 6: 130. PubMed Abstract | Publisher Full Text | Free Full Text

5. Karia R, Gupta I, Khandait H, et al.: CoVID-19 and its Modes of Transmission. SN Compr Clin Med. 2020; 1-4.

PubMed Abstract | Publisher Full Text | Free Full Text

6. Mondelli MU, Colaneri M, Seminari EM, et al.: Low risk of SARS-CoV-2 transmission by fomites in real-life conditions. Lancet Infect Dis. 2020; S1473-3099(20)30678-2.

PubMed Abstract | Publisher Full Text | Free Full Text

7. Rahman HS, Aziz MS, Hussein RH, et al:: The transmission modes and sources of COVID-19: A systematic review. Int J Surg Open. 2020; 26: 125-36. Publisher Full Text

8. Goldman E: Exaggerated risk of transmission of COVID-19 by fomites. Lancet Infect Dis. 2020; 20(8): 892-893. PubMed Abstract | Publisher Full Text | Free Full Tex

9. Onakpoya I, Heneghan C, Spencer EA, et al.: Extended data: SARS-CoV-2 and the Role of Fomite Transmission: A Systematic Review. figshare. Journal contribution. 2021.

http://www.doi.org/10.6084/m9.figshare.14247113.v1

10. Whiting PF, Rutjes AWS, Westwood ME, et al.: QUADAS-2: a revised tool for the quality assessment of diagnostic accuracy studies. Ann Intern Med. 2011;
155(8): 529-36.

PubMed Abstract | Publisher Full Text

11. Paton S, Spencer A, Garratt I, et al.: Persistence of SARS-CoV-2 virus and viral RNA on hydrophobic and hydrophilic surfaces and investigating contamination concentration. bioRxiv. 2021. Publisher Full Text

12. Boone SA, Gerba CP: Significance of fomites in the spread of respiratory and enteric viral disease. Appl Environ Microbiol. 2007; 73(6): 1687-96. PubMed Abstract | Publisher Full Text | Free Full Text

13. Dawson P, Malik MR, Parvez F, et al.: What Have We Learned About Middle East Respiratory Syndrome Coronavirus Emergence in Humans? A Systematic Literature Review. Vector Borne Zoonotic Dis. 2019; 19(3): 174-192. PubMed Abstract | Publisher Full Text | Free Full Text

14. Bin SY, Heo JY, Song MS, et al.: Environmental Contamination and Viral Shedding in MERS Patients During MERS-CoV Outbreak in South Korea. Clin Infect Dis. 2016; 62(6): 755-60.

PubMed Abstract | Publisher Full Text | Free Full Text

15. World Health Organization: Coronavirus disease (COVID-19) advice for the public. [Accessed 18th January, 2021]. Reference Source

16. Public Health England: Guidance COVID-19: cleaning in non-healthcare settings outside the home. Updated 16 October 2020. [Accessed 18th January, 2021]. Reference Source

17. Centers for Disease Control and Prevention: CoviD-19. How to Protect Yourself \& Others. [Accessed 18th January, 2021]. Reference Source

18. Cherrie JW, Cherrie MPC, Davis A, et al.: Contamination of air and surfaces in workplaces with SARS-CoV-2 virus: a systematic review. Reference Source

19. Zacharioudakis IM, Prasad PJ, Zervou FN, et al:: Association of SARS-CoV-2 Genomic Load with COVID-19 Patient Outcomes. Ann Am Thorac Soc. 2020. PubMed Abstract | Publisher Full Text 


\section{Open Peer Review}

\section{Current Peer Review Status:}

\section{Version 2}

Reviewer Report 03 June 2021

https://doi.org/10.5256/f1000research.56906.r86160

(C) 2021 Pitol Garcia A. This is an open access peer review report distributed under the terms of the Creative Commons Attribution License, which permits unrestricted use, distribution, and reproduction in any medium, provided the original work is properly cited.

\section{Ana Karina Pitol Garcia}

Department of Civil and Environmental Engineering, Imperial College London, London, UK The authors have addressed most of the major concerns.

I still believe that it's not clear what the authors mean by "bias". The authors used circular reasoning in their explanation; they state that they assessed "bias" by asking if the reviewed articles acknowledged "bias", but they never defined the term or mentioned the exact questions used to determine it.

Nevertheless, this article provides a good summary of the scientific publications that have survey SARS-CoV-2 on surfaces and is, therefore, a valuable contribution.

Competing Interests: No competing interests were disclosed.

Reviewer Expertise: Disease transmission, Quantitative Microbial Risk Assessment (QMRA), fomitemediated transmission, virus transfer.

I confirm that I have read this submission and believe that I have an appropriate level of expertise to confirm that it is of an acceptable scientific standard.

Reviewer Report 03 June 2021

https://doi.org/10.5256/f1000research.56906.r86161

(C) 2021 Goldman E. This is an open access peer review report distributed under the terms of the Creative Commons Attribution License, which permits unrestricted use, distribution, and reproduction in any medium, provided the original work is properly cited.

\section{Emanuel Goldman}


Department of Microbiology, Biochemistry and Molecular Genetics, New Jersey Medical School, Newark, NJ, USA

I'm still not entirely convinced that the "bias" parameter included in the analysis is useful, since there is some element of subjectivity in making that assessment. Nevertheless, the authors have given a fuller accounting of what's involved in this parameter, so at least, a reader can draw their own conclusions regarding alleged "bias".

Overall, the authors have appropriately responded to my comments and suggestions, and I am satisfied that this manuscript is now acceptable as a peer-reviewed publication and a useful contribution to the literature.

Competing Interests: No competing interests were disclosed.

Reviewer Expertise: Microbiology, Virology

I confirm that I have read this submission and believe that I have an appropriate level of expertise to confirm that it is of an acceptable scientific standard.

\section{Version 1}

Reviewer Report 11 May 2021

\section{https://doi.org/10.5256/f1000research.54776.r83869}

(c) 2021 Pitol Garcia A. This is an open access peer review report distributed under the terms of the Creative Commons Attribution License, which permits unrestricted use, distribution, and reproduction in any medium, provided the original work is properly cited.

\section{Ana Karina Pitol Garcia}

Department of Civil and Environmental Engineering, Imperial College London, London, UK

The authors compiled and summarized many scientific publications that surveyed SARS-CoV-2 on surfaces. Surface contamination is an essential piece of information needed to understand the role of fomites in disease transmission. The authors collected data on the presence of RNA and viable SARS-CoV-2. Notable, out of the 11 identified papers that attempted viral culture, none fund cytopathic effects. Therefore, no viable SARS-CoV-2 has been recovered from surfaces up to date. The review is comprehensive, timely, and valuable for understanding the relative contribution of fomite-mediated transmission to the spread of SARS-CoV-2.

\section{Major comments:}

\section{Methods}

The authors mention using an adapted version of "QUADAS-2 criteria" to assess the quality of the studies, but the exact methodology is not reported neither in the main article nor in the extended data. More transparency is needed regarding the exact questions used to determine quality and 
bias.

Additionally, the authors criticize publications that do not report "patient information" such as "symptom onset in the patients". Nevertheless, this information is not relevant in settings with no COVID-19 patients (surfaces at gas stations, bus stations, hospital wards, etc.).

\title{
Discussion
}

Regarding the following statement:

"The inability to culture the virus despite positive PCR detection tests may indicate either that surface contamination does not support viral growth and hence transmissibility or that the timing of collection was at a point of time where no viable virus would be likely to be found."

The first hypothesis is not clear, "The inability to culture the virus despite positive PCR detection tests may indicate either that surface contamination does not support viral growth and hence transmissibility" - We know that the virus needs a host cell to replicate. The capacity of fomites to serve as a vehicle for the transmission of SARS-CoV-2 depends on factors such as the decay rate of the virus on the surface and on the hands, the virus transfer rate (surface to hand, and hand to face), the frequency of touch between the hands and face, the dose-response curve of the virus, among other parameters. Even if the virus does not "grow" on the surface, there is still potential for transmission. Therefore, this sentence needs to be removed or clarified.

Second hypothesis: "The inability to culture the virus despite positive PCR detection tests may indicate ... that the timing of collection was at a point of time where no viable virus would be likely to be found." The authors suggest throughout the discussion that the 11 studies that cultured the virus showing not cytopathic effects have "significant fundamental methodological flaws" (which are not clearly pointed out in the manuscript), directing the reader to conclude that this is probably the reason why no attempt at culturing viruses from surfaces has been successful. It's helpful to point out that SARS-CoV-2 RNA is much more stable on fomites than infective SARS-CoV-2 virus, and it is found in much greater concentrations. For example, in an experimental study where SARS-CoV-2 was inoculated on surfaces, Paton et al. $(2021)^{1}$ found that the number of RNA recovered from the surfaces was $10^{3}$ to $10^{8}$ times higher than the number of viable virus in the samples. Given the relatively low concentration of RNA found on surfaces in the compiled articles, it is expected that the 11 studies that attempted to culture the virus could not find cytopathic effects. It is true, as the authors point out, that the transmission via fomites cannot be discarded. Nevertheless, the evidence that the authors compiled can already give an idea of how unlikely fomite-mediate transmission is in most settings.

\section{Minor comments:}

\author{
Abstract \\ Please, clarify the statement "SARS-CoV-2 has been detected in fomites..." by replacing it with "SARS- \\ CoV-2 RNA has been detected in fomites..."

\section{Introduction} \\ The statement, "it has been reported that SARS-CoV-2 can be transmitted indirectly through fomites or \\ surfaces." is not supported by the reference. The reference only suggests the possibility of fomite \\ transmission based on (1) the presence of SARS-CoV-2 RNA on surfaces, and (2) experimental \\ evidence of virus survival at specific conditions and high concentrations. Up to date, no study has
}


"reported" fomite-mediated transmission. Replacing the word "reported" by "suggested" would be better.

\section{Discussion}

In the following sentence, "We identified one non-peer-reviewed (pre-print) systematic review that assessed fomite contamination in SARS-CoV-2." perhaps what the authors intended to say was, "We identified one non-peer-reviewed (pre-print) systematic review that assessed SARS-CoV-2 contamination in fomites."?

\section{Figure 3}

It would be more informative for the reader if the plot could distinguish between public spaces and rooms with COVID-19 patients. The authors could break the "other" category and include "isolation or quarantine room", since the most frequently contaminated spaces were quarantine rooms.

\section{References}

1. Paton S, Spencer A, Garratt I, Thompson K, et al.: Persistence of SARS-CoV-2 virus and viral RNA on hydrophobic and hydrophilic surfaces and investigating contamination concentration. bioRxiv. 2021. Publisher Full Text

Are the rationale for, and objectives of, the Systematic Review clearly stated? Yes

Are sufficient details of the methods and analysis provided to allow replication by others? Partly

Is the statistical analysis and its interpretation appropriate?

Not applicable

Are the conclusions drawn adequately supported by the results presented in the review? Partly

Competing Interests: No competing interests were disclosed.

Reviewer Expertise: Disease transmission, Quantitative Microbial Risk Assessment (QMRA), fomitemediated transmission, virus transfer.

I confirm that I have read this submission and believe that I have an appropriate level of expertise to confirm that it is of an acceptable scientific standard, however I have significant reservations, as outlined above.

Author Response 14 May 2021

IGHO ONAKPOYA, University of Oxford, Oxford, UK

Peer reviewer's comment:

The authors compiled and summarized many scientific publications that surveyed SARS- 
CoV-2 on surfaces. Surface contamination is an essential piece of information needed to understand the role of fomites in disease transmission. The authors collected data on the presence of RNA and viable SARS-CoV-2. Notable, out of the 11 identified papers that attempted viral culture, none fund cytopathic effects. Therefore, no viable SARS-CoV-2 has been recovered from surfaces up to date. The review is comprehensive, timely, and valuable for understanding the relative contribution of fomite-mediated transmission to the spread of SARS-CoV-2.

Authors' response: Thank you.

\section{Peer reviewer's comment: Major comments: Methods}

The authors mention using an adapted version of "QUADAS-2 criteria" to assess the quality of the studies, but the exact methodology is not reported neither in the main article nor in the extended data. More transparency is needed regarding the exact questions used to determine quality and bias.

Authors' response: Now reads thus: "We assessed the risk of bias using five domains from the QUADAS-2 criteria [9]; we adapted this tool because the included studies were not designed as diagnostic accuracy studies. The domains assessed were: (i) study description was there sufficient description of methods to enable replication of the study? (ii) sample sources - was there a clear description of sample sources? (iii) description of results - was the reporting of study results and analysis appropriate? (iv) risk of bias - did the authors acknowledge any potential biases, if yes were any attempts made to address these biases? (v) applicability - is there any concern that the interpretation of test results differs from the study question? For each bias domain, the risk was judged as "low", "unclear" or "high"."

\section{Peer reviewer's comment:}

Additionally, the authors criticize publications that do not report "patient information" such as "symptom onset in the patients". Nevertheless, this information is not relevant in settings with no COVID-19 patients (surfaces at gas stations, bus stations, hospital wards, etc.).

Authors' response: Now reads thus: "The latter possibility is considered highly likely on the basis of culturing without the benefit of looking at the timing of the specimens with respect to symptom onset (in study settings that had SARS-CoV-2 positive patients) ..."

\section{Peer reviewer's comment: \\ Discussion}

Regarding the following statement:

"The inability to culture the virus despite positive PCR detection tests may indicate either that surface contamination does not support viral growth and hence transmissibility or that the timing of collection was at a point of time where no viable virus would be likely to be found."

The first hypothesis is not clear, "The inability to culture the virus despite positive PCR detection tests may indicate either that surface contamination does not support viral growth and hence transmissibility" - We know that the virus needs a host cell to replicate. The capacity of fomites to serve as a vehicle for the transmission of SARS-CoV-2 depends on factors such as the decay rate of the virus on the surface and on the hands, the virus transfer rate (surface to hand, and hand to face), the frequency of touch between the hands and face, the dose- 
response curve of the virus, among other parameters. Even if the virus does not "grow" on the surface, there is still potential for transmission. Therefore, this sentence needs to be removed or clarified.

Authors' response: We have revised the statement and added a reference. Now reads thus: "The inability to culture the virus despite positive PCR detection tests suggests that SARSCoV-2 RNA is more stable (and likely found in greater concentrations) on fomites than infective SARS-CoV-2 virus [11]". Factors known to affect the ability of fomites to serve as transmitters of respiratory viruses include the rate of decay of the virus on the surface and on the hands, the virus transfer rate (surface to hand, and hand to face), the frequency of touch between the hands and face, the dose-response curve of the virus, temperature and humidity, amongst others [12]."

\section{Peer reviewer's comment:}

Second hypothesis: "The inability to culture the virus despite positive PCR detection tests may indicate ... that the timing of collection was at a point of time where no viable virus would be likely to be found." - The authors suggest throughout the discussion that the 11 studies that cultured the virus showing not cytopathic effects have "significant fundamental methodological flaws" (which are not clearly pointed out in the manuscript), directing the reader to conclude that this is probably the reason why no attempt at culturing viruses from surfaces has been successful. It's helpful to point out that SARS-CoV-2 RNA is much more stable on fomites than infective SARS-CoV-2 virus, and it is found in much greater concentrations. For example, in an experimental study where SARS-CoV-2 was inoculated on surfaces, Paton et al. (2021) ${ }^{1}$ found that the number of RNA recovered from the surfaces was $10^{3}$ to $10^{8}$ times higher than the number of viable virus in the samples. Given the relatively low concentration of RNA found on surfaces in the compiled articles, it is expected that the 11 studies that attempted to culture the virus could not find cytopathic effects. It is true, as the authors point out, that the transmission via fomites cannot be discarded. Nevertheless, the evidence that the authors compiled can already give an idea of how unlikely fomite-mediate transmission is in most settings.

Authors' response: We have revised the statement.

\section{Peer reviewer's comment:}

\section{Minor comments:}

\section{Abstract}

Please, clarify the statement "SARS-CoV-2 has been detected in fomites..." by replacing it with "SARS-CoV-2 RNA has been detected in fomites..."

Authors' response: Added "RNA"

\section{Peer reviewer's comment: Introduction}

The statement, "it has been reported that SARS-CoV-2 can be transmitted indirectly through fomites or surfaces." is not supported by the reference. The reference only suggests the possibility of fomite transmission based on (1) the presence of SARS-CoV-2 RNA on surfaces, and (2) experimental evidence of virus survival at specific conditions and high concentrations. Up to date, no study has "reported" fomite-mediated transmission. Replacing the word "reported" by "suggested" would be better.

Authors' response: Agreed. This was already commented on by Reviewer 1 . We have 
revised as suggested.

\section{Peer reviewer's comment:}

Discussion

In the following sentence, "We identified one non-peer-reviewed (pre-print) systematic review that assessed fomite contamination in SARS-CoV-2." perhaps what the authors intended to say was, "We identified one non-peer-reviewed (pre-print) systematic review that assessed SARS-CoV-2 contamination in fomites."?

Authors' response: We have made the correction. Now reads thus: "We identified one nonpeer-reviewed (pre-print) systematic review that assessed SARS-CoV-2 contamination in fomites..."

\section{Peer reviewer's comment:}

\section{Figure 3}

It would be more informative for the reader if the plot could distinguish between public spaces and rooms with COVID-19 patients. The authors could break the "other" category and include "isolation or quarantine room", since the most frequently contaminated spaces were quarantine rooms.

Authors' response: We understand the reviewer's point here. However, we reported the settings are described by the study authors - only 2 studies were described as "hospital and quarantine". Therefore we have not made any changes to the figure.

Competing Interests: None

Reviewer Report 06 April 2021

\section{https://doi.org/10.5256/f1000research.54776.r82053}

(C) 2021 Goldman E. This is an open access peer review report distributed under the terms of the Creative Commons Attribution License, which permits unrestricted use, distribution, and reproduction in any medium, provided the original work is properly cited.

\section{Emanuel Goldman}

Department of Microbiology, Biochemistry and Molecular Genetics, New Jersey Medical School, Newark, NJ, USA

In this manuscript, the authors have conducted an extensive comparison of many published studies attempting to assess the possibility of transmission of SARS-CoV-2 via fomites. Most of the studies reviewed involved samples from hospitals, although some studies were also from community settings. The authors report that none of the studies found infectious virus on fomites, and that viral RNA, while generally present to varying degrees, was likely of too poor quality in most instances to support infectivity anyway, based on relatively high cycle threshold (CT) values for the RNA samples.

This is a useful snapshot of where we are in the pandemic, and why thinking in the field has 
increasingly moved towards the view that fomite transmission is not a significant source of infection. This reviewer believes the authors are too timid in drawing that conclusion, only stating in the Abstract "Lack of positive viral cultures and variation in cycle thresholds create uncertainty about fomites as a mode of transmission." I believe a more forceful statement about the insignificance of fomite transmission is warranted.

In the second paragraph of the Introduction, the authors do not adequately characterize the content of some of the references cited.

The authors write, "it has been reported that SARS-CoV-2 can be transmitted indirectly through fomites or surfaces ${ }^{5}$." This is inaccurate; reference 5 is a review of work published up to that time, and at most, suggests the possibility that the virus can be transmitted through fomites. None of the papers reviewed in reference 5 showed indirect transmission through fomites. The authors must revise this sentence. My suggestion is to replace "reported" with "suggested", i.e., "it has been suggested that SARS-CoV-2 can be transmitted indirectly through fomites or surfaces ${ }^{5}$."

The opposite situation occurs in the very next sentence. The authors write, "However, some authors have suggested that there is a low risk of transmission of SARS-CoV-2 through fomites ${ }^{6,7}$." Reference 6 is more than a suggestion; the authors report the absence of infectious virus on surfaces in hospitals treating COVID-19 patients. My suggestion here is the reverse of my previous one, in this case, replace "suggested" with "reported" for reference 6, i.e., "However, some authors have reported $^{6}$ or suggested ${ }^{7}$ that there is a low risk of transmission of SARS-CoV-2 through fomites."

In the last paragraph of the methods section, the authors write: "One reviewer (IJO) assessed the risk of bias and extracted data from the included studies, and these were independently checked by a second reviewer (EAS)." However, the reader is not given a clue as to what the authors mean by "bias" in this context. The absence of a definition and/or criteria for alleged "bias" makes this parameter meaningless in the manuscript. If the authors are to include this parameter, they must revise the manuscript to make clear what it is they are assessing as "bias", and how that assessment was made.

Are the rationale for, and objectives of, the Systematic Review clearly stated? Yes

Are sufficient details of the methods and analysis provided to allow replication by others? Partly

Is the statistical analysis and its interpretation appropriate?

Yes

Are the conclusions drawn adequately supported by the results presented in the review? Yes

Competing Interests: No competing interests were disclosed.

Reviewer Expertise: Microbiology, Virology 


\section{I confirm that I have read this submission and believe that I have an appropriate level of expertise to confirm that it is of an acceptable scientific standard, however I have significant reservations, as outlined above.}

Author Response 12 Apr 2021

IGHO ONAKPOYA, University of Oxford, Oxford, UK

We thank the reviewer for the useful feedback regarding our manuscript. In line with the reviewer's suggestions, we will be making the following revisions to the manuscript:

\section{ABSTRACT}

We will revise the conclusions to reflect the results that the risk of transmission of SARSCoV-2 through fomites is low.

\section{METHODS}

In the second paragraph, we will replace "reported" with "suggested" (ref. 5) and replace "suggested" with "reported" (refs. 6\&7).

In the last paragraph of this section, we will expand the reporting of the methods used for risk of bias assessment - we will include the domains of bias assessed and how each domain was scored.

\section{Competing Interests: None}

\section{Author Response 14 May 2021}

IGHO ONAKPOYA, University of Oxford, Oxford, UK

\section{Peer Reviewer's comment:}

In this manuscript, the authors have conducted an extensive comparison of many published studies attempting to assess the possibility of transmission of SARS-CoV-2 via fomites. Most of the studies reviewed involved samples from hospitals, although some studies were also from community settings. The authors report that none of the studies found infectious virus on fomites, and that viral RNA, while generally present to varying degrees, was likely of too poor quality in most instances to support infectivity anyway, based on relatively high cycle threshold (CT) values for the RNA samples.

This is a useful snapshot of where we are in the pandemic, and why thinking in the field has increasingly moved towards the view that fomite transmission is not a significant source of infection.

Authors' response: Thank you.

\section{Peer Reviewer's comment:}

This reviewer believes the authors are too timid in drawing that conclusion, only stating in the Abstract "Lack of positive viral cultures and variation in cycle thresholds create uncertainty about fomites as a mode of transmission." I believe a more forceful statement about the insignificance of fomite transmission is warranted. 
Authors' response: We agree with the reviewer and have revised the statement. Abstract conclusion now reads thus: "Lack of positive viral cultures suggests that the risk of transmission of SARS-CoV-2 through fomites is low."

\section{Peer Reviewer's comment:}

In the second paragraph of the Introduction, the authors do not adequately characterize the content of some of the references cited.

The authors write, "it has been reported that SARS-CoV-2 can be transmitted indirectly through fomites or surfaces ${ }^{5}$." This is inaccurate; reference 5 is a review of work published up to that time, and at most, suggests the possibility that the virus can be transmitted through fomites. None of the papers reviewed in reference 5 showed indirect transmission through fomites. The authors must revise this sentence. My suggestion is to replace "reported" with "suggested", i.e., "it has been suggested that SARS-CoV-2 can be transmitted indirectly through fomites or surfaces ${ }^{5}$

Authors' response: We have amended the sentence. Now reads thus: “... it has been suggested that SARS-CoV-2 can be transmitted indirectly through fomites or surfaces..."

\section{Peer Reviewer's comment:}

The opposite situation occurs in the very next sentence. The authors write, "However, some authors have suggested that there is a low risk of transmission of SARS-CoV-2 through fomites 6,7 ." Reference 6 is more than a suggestion; the authors report the absence of infectious virus on surfaces in hospitals treating COVID-19 patients. My suggestion here is the reverse of my previous one, in this case, replace "suggested" with "reported" for reference 6, i.e., "However, some authors have reported ${ }^{6}$ or suggested $^{7}$ that there is a low risk of transmission of SARS-CoV-2 through fomites."

Authors' response: We have amended the sentence. Now reads thus: "... some authors have reported that there is a low risk of transmission of SARS-CoV-2 through fomites $[6,7]$ and others have reported that the risk of such transmission is exaggerated [8]".

\section{Peer Reviewer's comment:}

In the last paragraph of the methods section, the authors write: "One reviewer (IJO) assessed the risk of bias and extracted data from the included studies, and these were independently checked by a second reviewer (EAS)." However, the reader is not given a clue as to what the authors mean by "bias" in this context. The absence of a definition and/or criteria for alleged "bias" makes this parameter meaningless in the manuscript. If the authors are to include this parameter, they must revise the manuscript to make clear what it is they are assessing as "bias", and how that assessment was made.

Authors' response: We have expanded the section on risk of bias assessment. Now reads thus: "We assessed the risk of bias using five domains from the QUADAS-2 criteria [9]; we adapted this tool because the included studies were not designed as diagnostic accuracy studies. The domains assessed were: (i) study description - was there sufficient description of methods to enable replication of the study? (ii) sample sources - was there a clear description of sample sources? (iii) description of results - was the reporting of study results and analysis appropriate? (iv) risk of bias - did the authors acknowledge any potential biases, if yes were any attempts made to address these biases? (v) applicability - is there any concern that the interpretation of test results differs from the study question? For each bias 
domain, the risk was judged as "low", "unclear" or "high"."

Competing Interests: None

The benefits of publishing with F1000Research:

- Your article is published within days, with no editorial bias

- You can publish traditional articles, null/negative results, case reports, data notes and more

- The peer review process is transparent and collaborative

- Your article is indexed in PubMed after passing peer review

- Dedicated customer support at every stage

For pre-submission enquiries, contact research@f1000.com 